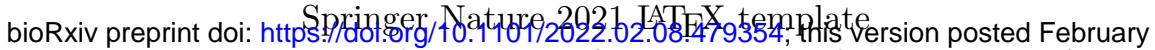
10,2022 . The copyright holder for this preprint (which was not certified by peer review) is the author/funder. All rights reserved. No reuse allowed without permission.

\title{
Loss of SUMO-specific protease 2 causes isolated glucocorticoid deficiency by blocking zonal transdifferentiation
}

Damien Dufour ${ }^{1}$, Typhanie Dumontet ${ }^{1,2,3}$, Isabelle Sahut-Barnola ${ }^{1}$, Meline Onzon ${ }^{1}$, Eric Pussard ${ }^{4}$, James Jr

Wilmouth $^{1}$, Julie Olabe ${ }^{1}$, Cecily Lucas ${ }^{1,5}$, Adrien Levasseur $^{1}$, Jean-Christophe Pointud ${ }^{1}$, Florence RoucherBoulez $^{1,5}$, Igor Tauveron ${ }^{1,6}$, Guillaume Bossis ${ }^{7}$, Edward T.

Yeh $^{8}$, David T. Breault ${ }^{9,10}$, Pierre Val ${ }^{1}$, Anne-Marie Lefrançois-Martinez $^{1}$ and Antoine Martinez ${ }^{1 *}$

${ }^{1}$ institut Génétique, Reproduction \& Développement (iGReD), CNRS, INSERM, Université Clermont Auvergne,

Clermont-Ferrand, F-63000, France.

${ }^{2}$ Department of Internal Medicine, Division of Metabolism, Endocrinology, and Diabetes, University of Michigan, Ann Arbor, Michigan, USA.

${ }^{3}$ Training Program in Organogenesis, Center for Cell Plasticity and Organ Design, University of Michigan, Ann Arbor, Michigan, USA.

${ }^{4}$ Service de Génétique Moléculaire, Pharmacogénétique et Hormonologie, Hôpital de Bicêtre, Assistance Publique-Hôpitaux de Paris (APHP), Physiologie et Physiopathologie Endocriniennes, INSERM, Université Paris-Saclay, Le Kremlin-Bicêtre, France. ${ }^{5}$ Endocrinologie Moléculaire et Maladies Rares, Centre Hospitalier Universitaire, Université Claude Bernard Lyon 1, Bron, France.

${ }^{6}$ Service d'Endocrinologie, Centre Hospitalier Universitaire

Gabriel Montpied, Université Clermont Auvergne,

Clermont-Ferrand, France.

${ }^{7}$ IGMM, Université de Montpellier, CNRS, Montpellier, France. ${ }^{8}$ Division of Endocrinology, Boston Children's Hospital, Department of Pediatrics, Harvard Medical School, Boston, Massachusetts, USA. 
bioRxiv preprint doi: httpspringer / fort 10,2022 . The copyright holder for this preprint (which was not certified by peer review) is the author/funder. All rights reserved. No reuse allowed without permission.

\title{
2 SENP2 controls adrenal cortex homeostasis
}

${ }^{9}$ Harvard Stem Cell Institute, Harvard University, Cambridge, Massachusetts, USA.

${ }^{10}$ Department of Internal Medicine, University of Arkansas for Medical Sciences, Little Rock, Arkansas, USA.

*Corresponding author(s). E-mail(s): antoine.martinez@uca.fr; Contributing authors: damien.dufour@doctorant.uca.fr; tdumonte@med.umich.edu; isabelle.barnola@uca.fr; meline.onzon@etu.uca.fr ; eric.pussard@aphp.fr; jwilmouth21@gmail.com; julie.olabe@gmail.com; cecily.lucas6@gmail.com; Adrien.levasseur@uca.fr; j-christophe.pointud@uca.fr; florence.roucher@chu-lyon.fr; itauveron@chu-clermontferrand.fr;

guillaume.bossis@igmm.cnrs.fr; dredyeh@gmail.com; david.breault@childrens.harvard.edu; pierre.val@uca.fr; a-marie.lefrancois-martinez@uca.fr;

\begin{abstract}
SUMOylation is a rapidly evolving posttranslational modification, that provides fine-tuning of protein function involved in cellular response to stress, differentiation, and tissue development. In the adrenal cortex, an emblematic endocrine player in adaptation to physiological demands, the SUMOylation gradient is inversely correlated with the differentiation flow. This raises the question of its role on functional zonation and stress response. Considering that SUMO-specific protease 2 (SENP2), a deSUMOylating enzyme, is upregulated by ACTH/PKA signalling, we generated mice with adrenal-specific Senp2 invalidation to address this question. SENP2 activity disruption in steroidogenic cells leads to specific hypoplasia of zona fasciculata, blunted cortical ACTH-responsiveness and isolated glucocorticoid deficiency. Mechanistically, overSUMOylation upon SENP2 loss shifts the balance between $\mathrm{ACTH} / \mathrm{PKA}$ and $\mathrm{WNT} / \beta$-catenin antagonistic pathways by repressing PKA catalytic activity and promoting ectopic $\beta$-catenin activation. This results in blocking the ability of zona glomerulosa cells to transdifferentiate into fasciculata and sensitises the latter to premature apoptosis. Our findings suggest that the SUMO pathway is instrumental for adrenal zone homeostasis and stress response.
\end{abstract}

Keywords: Adrenal, SUMO, SENP2, $\beta$-catenin, PKA, DRP1 
bioRxiv preprint doi: httpspringer / fort 10,2022 . The copyright holder for this preprint (which was not certified by peer review) is the author/funder. All rights reserved. No reuse allowed without permission.

SENP2 controls adrenal cortex homeostasis

The adrenal cortex is a constantly self-renewed endocrine organ composed of concentric zones, the outermost layer zona glomerulosa $(\mathrm{zG})$ producing mineralocorticoids and the inner zona fasciculata (zF) producing glucocorticoids. According to the centripetal cell turnover model taking place postnatally, progenitors cell populations located in the outer capsule characterised by GLI1 expression or within the $\mathrm{zG}$ expressing $\mathrm{SHH}$ consecutively differentiate into steroid-producing $\mathrm{zG}$ cells, then migrate inward, convert into $\mathrm{zF}$ cells and eventually die by apoptosis at the corticomedullary junction [1-3]. Genetic models and in vitro approaches have identified two important signalling pathways for adrenal cortex homeostasis. On one hand, the WNT/Rspondin/ $\beta$-catenin pathway is necessary for the maintenance of progenitor pools and the acquisition of $\mathrm{zG}$ identity [4-6]. On the other hand, cAMP/PKA signalling, stimulated by pituitary ACTH, triggers the recruitment of progenitors by inducing the transdifferentiation of zG cells into zF cells and stimulates glucocorticoids production [7, 8]. We and others have previously shown that these two signalling pathways antagonise each other by modulating various actors such as WNT4, PDE2A or CCDC80 $[3,6,9]$. Optimal response to PKA signalling and therefore zF differentiation is also subject to epigenetic programming by the histone methyl transferase EZH2 [10]. Nonetheless, the mechanisms that maintain adrenal cortex zonation and balance between these two pathways are yet to be discovered.

SUMOylation is a dynamic and one of the fastest evolving [11] posttranslational modification consisting in the covalent addition of SUMO peptides on a target protein. This modification can affect various processes such as protein stability, interactions or subcellular localisation [12]. There are three main SUMO peptides in rodents, namely SUMO1, which shares around $50 \%$ of identity with SUMO2 and SUMO3, the two latter differing by only three amino acids. SUMOylation is achieved through an enzymatic cascade involving activation by the E1 heterodimer (SAE1/UBA2), conjugation by the sole E2 enzyme UBC9 (encoded by Ube2i) and final ligation by various E3 SUMO ligases such as members of the PIAS and TRIM families as well as RANPBP2 and CBX4 $[13,14]$. SUMO peptides can be removed from SUMO-conjugated substrates by deSUMOylase belonging mainly to the Sentrin-specific proteases family (SENPs) or more recently discovered DeSI-1 and USPL1 making this posttranslational modification highly dynamic (Figure S1.A. S1.B.). Several in vitro and in vivo studies have highlighted the importance of controlling SUMOylation levels to enable differentiation or maintain cellular identity [1517] and tissue homeostasis in vivo in various cell lineages [18, 19]. The adrenal gland could provide a paradigm to study how SUMOylation dynamics can interact with the function and homeostasis of an organ in charge of constant adaptation to stress.

We have previously shown that protein SUMOylation follows a decreasing centripetal gradient in human and mouse normal adrenal cortices. Moreover, this gradient is altered in genetic endocrine diseases with deregulated PKA 
bioRxiv preprint doi: httpspringer / fort 10,2022 . The copyright holder for this preprint (which was not certified by peer review) is the author/funder. All rights reserved. No reuse allowed without permission.

or WNT signalling pathways [20]. Remarkably, SUMOylation is negatively and acutely regulated by ACTH in both adrenal cortex and adrenocortical cell cultures through transcriptional control of key enzymes, especially SENP2 whose upregulation by PKA correlates with transient hypoSUMOylation in zF. Interestingly, PKA-mediated up-regulation of Senp2 was previously shown to promote the progression of preadipocytes into the adipogenic program [15]. Taken together, these studies suggest that limiting SUMOylation may facilitate or be a prerequisite for any change in differentiation states. Conversely, an excess of WNT/ $\beta$-catenin signalling in the adrenal cortex induces an expansion of $\mathrm{zG}$ identity that was correlated with a high SUMOylation state [20]. Finally, preventing in vivo SUMOylation of the transcription factor SF1 $\left(S F 1^{2 K R / 2 K R}\right.$ mice), the main driver of adrenogonadal cell fate, disturbs endocrine development by maintaining discrete gonadal traits in the cortex and adrenal traits in the testis [21]. This highlights the need to control SUMOylation during cell fate decision leading to adrenal cortex identity.

We hypothesise that disruption of the SUMOylation gradient in the adrenal cortex may disrupt zonation and impair adaptive response to stress. In order to understand the implication of SUMO pathway on homeostatic maintenance and endocrine function, we have developed mouse models of adrenal hyperSUMOylation by conditional ablation of Senp2 in the cortex $\left(S e n p 2^{c K O}\right)$. Our report reveals that Senp2 $2^{c K O}$ mice harbour zone-specific adrenal atrophy, isolated glucocorticoid deficiency and blunted response to ACTH. Progressive atrophy of zF evoked by SENP2 deficiency results from a blockade of zonal transdifferentiation, early apoptosis and impaired PKA catalytic activity that cannot be rescued by genetic de-repression of the PKA holoenzyme. SENP2-deficient adrenals also show increased $\beta$-catenin SUMOylation and activity that may contribute to antagonising PKA signalling and maintaining the suppression of $\mathrm{zF}$ identity. Taken together, our data identify SUMOylation as a feedforward mechanism of adrenal homeostasis controlling zonal differentiation and stress responsiveness in part through the reversible activation of $\beta$-catenin and repression of PKA catalytic activity.

\section{Results}

\section{Senp2 invalidation in the adrenal cortex leads to $\mathrm{zF}$ hypoplasia and adrenal dysplasia}

To assess the role of SUMOylation in the adrenal cortex, we developed a mouse model with specific deletion of the ACTH-regulated deSUMOylase SENP2 [20] in steroidogenic cells by mating Senp2fl/fl mice [22] with Sf1(Nr5a1)-Cre mice [23]. Senp2 conditional knock-out mice are later referred to as Senp2 $2^{c K O}$. Senp2 deletion was confirmed in 4 -week-old mouse adrenals by RT-qPCR analyses showing reduced Senp2 mRNA accumulation in both genders and by genomic PCR, confirming adrenal-specific recombination at the Senp2 locus. (Figure S1.C.D.). 
bioRxiv preprint doi: httpspringer / fort 10,2022 . The copyright holder for this preprint (which was not certified by peer review) is the author/funder. All rights reserved. No reuse allowed without permission.

Monitoring of adrenal mass from 4 to 40 weeks of age revealed significant adrenal hypoplasia in mutants, occurring between 4 and 8 weeks in both sexes. After this time point, overall adrenal weight in Senp2cKO remained below that of controls in females only because of sex differences in the kinetics of adrenal mass gain (almost continuous growth in WT females contrasting with a progressive decrease in WT males over time) (Figure 1.A.). To investigate the causes of this hypoplasia, we performed Haematoxylin \& Eosin staining, which revealed two different histologic phenotypes: either homogeneous atrophy of the cortex leaving medulla centrally located, or cortical atrophy accompanied by dysplasia due to clusters of large eosinophilic cells, usually at one pole of the gland and pushing the medulla toward the other pole. (Figure 1.B. left panel).

Immunofluorescence co-staining for zonal markers showed that, compared to WT, the integrity of zG (DAB2+) did not seem affected in Senp2 ${ }^{c K O}$ adrenals of 8 -week-old mice, while zF (AKR1B7+) was atrophic and sometimes mislocated together with the medulla $(\mathrm{TH}+)$ in dysplastic glands (Figure 1.B. right panels). To confirm that the $\mathrm{zF}$ was the most affected by Senp2 invalidation, the number of cells in each cortical zones and medulla was counted on $2 \mathrm{D}$ sections. This showed a dramatic and specific reduction in total cortical cell number regardless of sex, solely attributable to the $75-80 \%$ loss of zF cells (Figure 1.C., S1.E). Laminin immunostaining was then used to examine vascular architecture in WT and mutant adrenal sections. Typical capillaries surrounding the "rosette" structures in the zG and delimiting the zF cells columns were evidenced in WT adrenal sections. Consistent with zonal markers immunostaining, a rosette-like pattern of vascularisation, typical of $\mathrm{zG}$, was found in areas with atrophic $\mathrm{zF}$, whereas large columnar structures surrounding clusters of hypertrophic $\mathrm{zF}$ cells were evidenced in dysplastic Senp2-deficient glands (Figure 1.B. right panels).

To further characterise the origin of adrenal dysplasia, we introduced the Rosa26RmTmG reporter transgene [24] (Figure S1.F.) into Senp2 $2^{c K O}$ background to trace Senp2 recombination using GFP immunostaining and non-recombined cells using Tomato immunostaining. WT adrenals (from Sf1Cre/+ ::Senp2 $2^{f l /+}:: R 26 R^{m T m G / m T m G}$ triple transgenic mice) presented full recombined cortex, while in dysplastic Senp2 $2^{c K O}$ adrenals $(S f 1-C r e /+::$ Senp2 $2^{f l / f l}:: R 26 R^{m T m G / m T m G}$ ), most of the cells belonging to the mislocated zF were GFP-negative/tomato-positive, hence non recombined (Figure 1.D). To address the identity of these cells escaping recombination, we performed co-staining of GFP with the canonical steroidogenic marker SF-1. Surprisingly, GFP-negative cells expressed SF-1, implying that they kept full steroidogenic identity (Figure 1.D bottom centre panel) as also suggested by detection of zonal markers (Figure 1.B right panels, bottom). To confirm that these cells were hypertrophic as $\mathrm{H} \& \mathrm{E}$ and Laminin staining suggested, we measured 2D cell areas in the $\mathrm{zF}$ of WT and Senp2 ${ }^{c K O}$ adrenal sections. This showed that in females, although GFP-positive and GFP-negative $\mathrm{zF}$ cell areas did not differ in mutants, GFP-negative cells were larger than zF cells from WT adrenals (Figure 1.E). Similar observations were made in males but with a $P$-value 


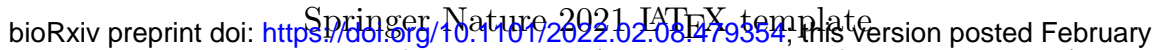
10,2022 . The copyright holder for this preprint (which was not certified by peer review) is the author/funder. All rights reserved. No reuse allowed without permission.
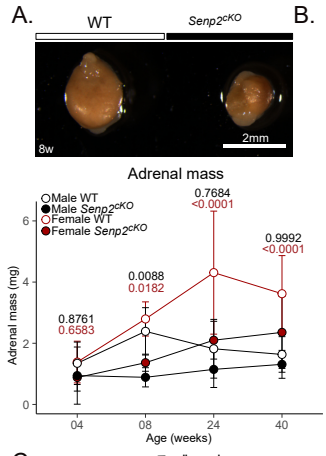

C.
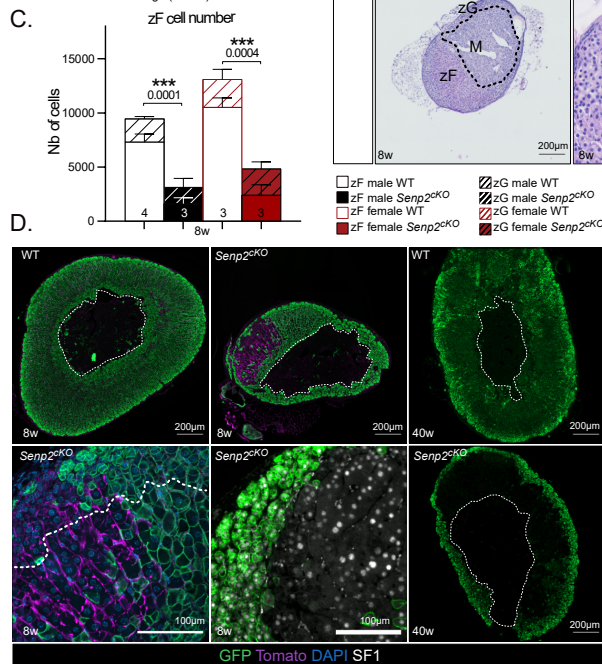
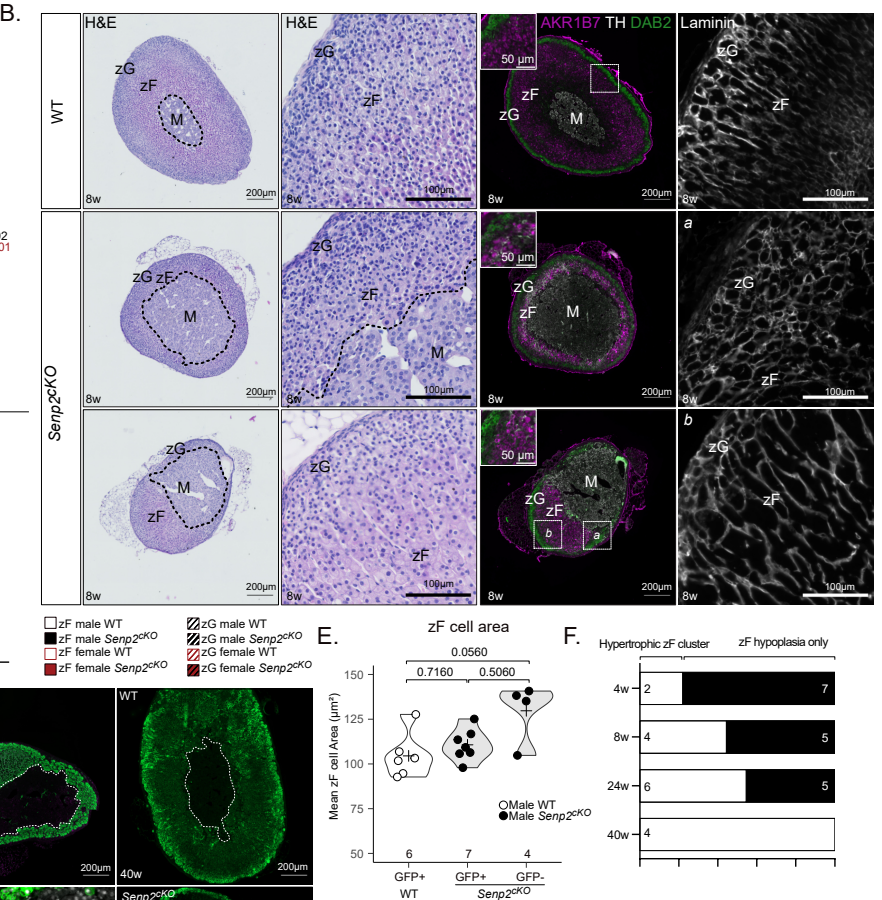

Hypertrophic zF cluster zF hypoplasia only
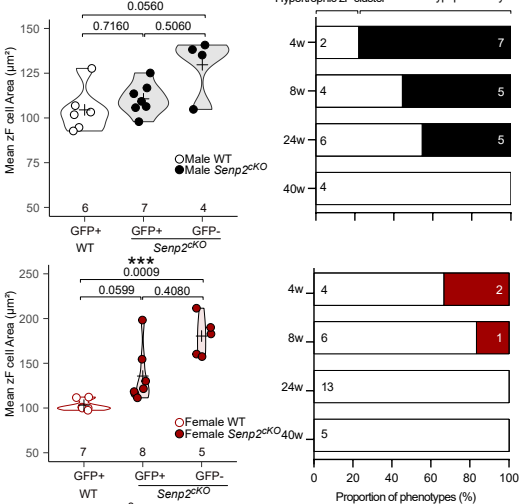

Fig. 1: Deletion of the deSUMOylase Senp2 in embryonic steroidogenic cells induces adrenal dysplasia and $\mathrm{zF}$ hypoplasia in adult mice.

A. Top : Representative picture of an 8-week-old WT (left) and a Senp2 $2^{c K O}$ (right) adrenal.

Bottom : Absolute adrenal mass follow-up of male and female mice WT and Senp2 ${ }^{c K O}$ (mean) from 4 to 40 weeks of age. $P$-values represent difference between genotypes within the same age and sex group.

B. Morphological analysis of the phenotypes on 8-week-old males' adrenals. Left : H\&E staining of WT or Senp2 $2^{c K O}$ adrenals with or without dysplasia. Center : Coimmunofluorescence labelling of AKR1B7 (green), TH/Tyrosine Hydroxylase (white) and DAB2/Disabled2 (Purple) in WT and Senp $2^{c K O}$ adrenals. Right : Immunofluorescence analysis of laminin (white) revealing the vascular network in WT and cKO adrenals.

C. $2 \mathrm{D}$ cell number counting in male and female adrenals at 8 weeks of age.

D. Coimmunofluorescence labelling of GFP (green) with Tomato (purple) and SF1 (white) at 8 (left and center) and 40 weeks of age (right) WT and $S e n p 2^{c K O}$ adrenals.

E. Morphometric analysis of $\mathrm{zF}$ cells area in WT $(\mathrm{GFP}+)$ adrenals and recombined $(\mathrm{GFP}+)$ or non recombined (GFP-) zones of $S e n p 2^{c K O}$ adrenals at 8 weeks of age.

F. Prevalence of phenotypes in cKO adrenals at different ages. Black (male) or red (female) bars represent hypoplastic adrenals without any gross morphological change and white bar represents hypoplastic and dysplastic adrenals harbouring hypertrophic zF clusters.

zG, zona glomerulosa; zF, zona fasciculata; WT, wild-type; cKO, conditional Knock-Out.

of 0.0560. Next, we assessed global SUMOylation status by western blot and found no variation in the profile of SUMO1 or SUMO2/3 conjugates depending 
bioRxiv preprint doi: httpspringer / fort 10,2022 . The copyright holder for this preprint (which was not certified by peer review) is the author/funder. All rights reserved. No reuse allowed without permission.

on the genotype (Figure S1.G.H.). However, GFP-positive zF cells retained nuclear SUMO2/3 staining whereas GFP-negative had diffuse staining in the cytoplasm (Figure S1.I.J.). Together, these results indicate that the clusters of cellular hypertrophy found in dysplastic Senp2 $2^{c K O}$ adrenals are predominantly composed of zF cells that have escaped Senp2 ablation and that this phenotype (hypertrophic zF clusters) seems more likely to occur in females. To examine further this sexual dimorphism, we assessed, in both genders, the proportion of mutant adrenals presenting with hypertrophic zF clusters from 4 to 40 weeks of age (Figure 1.F). Throughout time, the frequency of adrenals with hypertrophic $\mathrm{zF}$ clusters increased in a sexually dimorphic fashion: indeed, for these clusters to develop in all adrenals, it took 40 weeks in males and only 24 in females. Thus, in 40-week-old mice, Senp2 $2^{c K O}$ adrenal cortex contained, compared to WT, very few GFP-positive zF cells, with GFP staining limited to $\mathrm{zG}$ and non-recombined cells constituting the entire $\mathrm{zF}$ (Figure 1.D right panel S1.K).

Altogether, these results show that SENP2 is necessary for proper adrenal cortex zonation and homeostatic maintenance. Indeed, its inactivation leads initially, to zF atrophy, which is overwhelmed over time by the recruitment of cells escaping Senp2 recombination allowing them to maintain a wild-type Senp2 zF in otherwise mutant adrenals. Importantly, we show that females are more prone to overcome $\mathrm{zF}$ atrophy induced by Senp2 loss, again highlighting the sexually dimorphic traits of adrenal homeostasis [25, 26].

\section{Loss of SENP2 is associated with isolated glucocorticoid deficiency}

Given the profound alterations and notably, the time and sex-dependant remodelling of adrenal cortex zonation in $S e n p \mathcal{2}^{c K O}$, we measured changes in circulating steroid levels and assessed steroidogenic gene expression. Steroid hormones are synthesised from cholesterol through enzymatic processes resulting in corticosterone production by $\mathrm{zF}$ cells and aldosterone by $\mathrm{zG}$ cells (Figure 2.A.). Since zF was the most impacted zone by the Senp2 mutation, we anticipated a reduction in plasmatic corticosterone levels, the main glucocorticoid in rodents. Compared to WT males, corticosterone levels were indeed collapsed in Senp2 $2^{c K O}$ at 4 weeks, remained lower at 8 weeks of age but, interestingly, levels normalised over time to be indistinguishable from controls by 24 weeks (Figure 2.B. top). By contrast, there were no apparent differences in corticosterone levels in females across genotypes. (Figure 2.B. bottom). The integrity of the $\mathrm{zF}$ and the corticosterone production are under the strict control of pituitary ACTH that maintains homeostasis through a negative feedback loop mediated by the glucocorticoids on the hypothalamicpituitary-adrenals (HPA) axis. Therefore, we measured circulating ACTH in Senp2 $2^{c K O}$ and found a strong increase (8-10-fold increase) at 24 weeks in both sexes, consistent with a malfunction of zF cells eventually evolving toward a subclinical insufficiency (Figure 2.C.). 


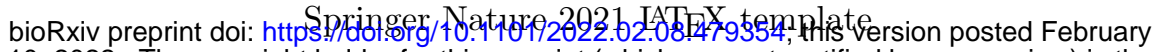
10,2022 . The copyright holder for this preprint (which was not certified by peer review) is the author/funder. All rights reserved. No reuse allowed without permission.

A.

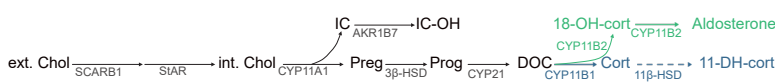

B.
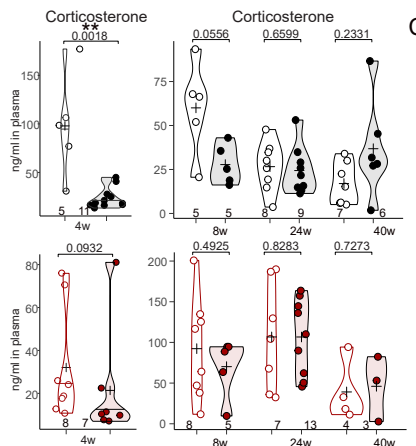
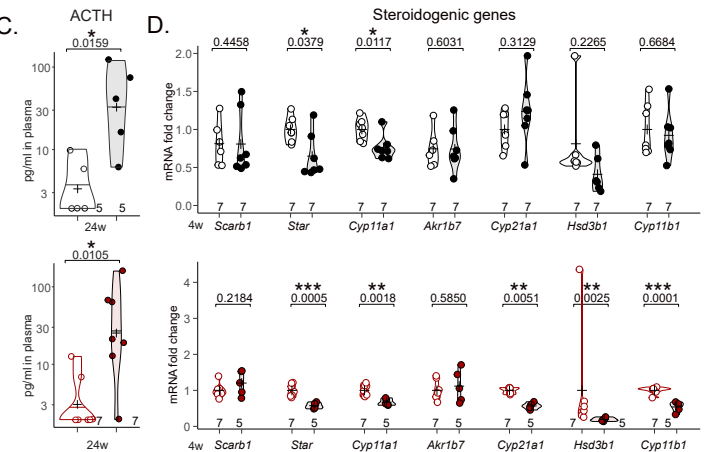

Fig. 2: Senp2 invalidation induces isolated glucocorticoid insufficiency.

A. Schematic representation of gluco- (blue) and mineralo- (green) corticoids synthesis : ext.Chol/int.Chol, extra/intracellular cholesterol; Preg, pregnenolone; Prog, progesterone; DOC, 11-deoxy-corticosterone; cort, corticosterone; 18-OH-cort, 18-hydroxycorticosterone; including detoxication of cholesterol side-chain clivage IC (Isocaproaldehyde) into IC-OH (isocapryl alcohol) and inactivation of corticosterone into 11-DH-cort (11-dehydrocorticosterone).

B. Plasmatic concentration of corticosterone in WT and Senp $2^{c K O}$ at 4 (determined by ELISA), 8, 24 and 40 weeks of age (determined by LC-MS/MS).

C. ACTH plasmatic levels of 24 -week-old WT and Senp2 $2^{c K O}$ mice.

D. qPCR analyses of steroidogenic genes mRNA accumulation in 4-week-old WT and Senp2 $2^{\text {cKO }}$ mice.

For insights into the mechanisms of this insufficiency, we analysed the expression of steroidogenic genes in adrenals of 4-week-old mice. RT-qPCR analyses showed that mRNA levels of Star and Cyp11a1 encoding rate limiting step proteins in steroidogenesis, were decreased in both male and female Senp $2^{c K O}$ adrenals (Figure 2.D.). Although, no other steroidogenic genes appeared to have altered expression in males at that time, Cyp21a1, Hsd3b1 and Cyp11b1 transcripts were specifically downregulated in female Senp $2^{c K O}$ adrenals (Figure 2.D). To assess the impact of Senp2 loss on zG function, we measured mineralocorticoids plasma levels and Cyp11b2 expression. Consistently with histological observations, we did not find any negative effect of Senp2 ablation on aldosterone levels, but rather a positive trend with an increase in 18-hydroxy-corticosterone plasmatic concentration in Senp $2^{c K O}$ male at 24 weeks and a trend toward upregulation of Cyp11b2 expression in Senp $2^{c K O}$ female adrenals at 4 weeks (Figure S2.A.B.C.).

In conclusion, these results draw a picture of the differential role of Senp2 in the zonation of the adrenal cortex. While it is dispensable for the $z G$, its absence leads to a deficient $\mathrm{zF}$ struggling to produce enough corticosterone to maintain homeostasis. This effort is illustrated by elevated circulating ACTH and hypertrophic zF cells, hallmarks of isolated glucocorticoid deficiency. 
bioRxiv preprint doi: httpsphinger / No 10,2022 . The copyright holder for this preprint (which was not certified by peer review) is the author/funder. All rights reserved. No reuse allowed without permission.

SENP2 controls adrenal cortex homeostasis

\section{Adrenal cortex lacking Senp2 shows blunted ACTH response}

Knowing that ACTH is a regulator of SUMOylation in the adrenal cortex [20] and that $\mathrm{zF}$ homeostasis is impaired in Senp2 $2^{c K O}$ mice, we assessed the endocrine and transcriptional steroidogenic responses to acute ACTH stimulation. Plasma concentrations of steroids associated with glucocorticoid metabolism (Figure 2.A.) were determined by LC-MS/MS, in 24-week-old mice injected 2 hours before with ACTH and compared to vehicle (Figure 3.A. Table S1). We confirmed that, at this age, there were no differences in plasma levels of all steroids measured in basal conditions (vehicle) between WT and Senp2 $2^{c K O}$ mice. As expected, ACTH treatment induced a strong increase in adrenal steroids (e.g. corticosterone levels were 3- to 7-fold induced in females and males, respectively) in plasma from WT mice (except progesterone in females, which comes mainly from the ovaries). However, the ACTH-stimulated endocrine response was heavily blunted and at least halved in Senp2 ${ }^{c K O}$ mice (Table S1.). To determine whether alteration of endocrine response correlated with changes in gene expression, we measured mRNA levels of ACTH-responsive genes involved in initial steps of steroidogenesis (i.e. Scarb1 and Star) by RT-qPCR (Figure 3.B.). In males, Senp2 mutation did not alter Scarb1 and Star transcriptional responsiveness to ACTH (1.5- to 2fold induction after $2 \mathrm{~h}$ ) but impaired their basal expression, so that mRNA levels in ACTH-treated mutant adrenals barely reached basal expression in controls. By contrast in females, although their basal expression remained unchanged, both Scarb1 and Star genes entirely failed to respond to ACTH in Senp2 $2^{c K O}$ adrenals (Figure 3.B.). To test whether this blunted transcriptional response relied on changes in activation of PKA substrates (Figure S3.A.), we performed western blots on trans-acting factor CREB and SUMO E3 ligase TRIM28 in response to $30 \mathrm{~min}$ ACTH treatment in WT and mutant mice. Ser133 CREB and Ser473 TRIM28 phosphorylation levels were similar in basal conditions, increased in WT upon ACTH stimulation but failed to respond to treatment in Senp2 $2^{c K O}$ adrenals (Figure 3.C). This impaired response to ACTH/PKA-mediated phosphorylation was unlikely caused by altered expression of ACTH receptor and co-receptor (Mc2r and Mrap, respectively) that remained unchanged by Senp2 loss (Figure S3.B.).

To determine whether the deficiency in ACTH response involved PKA holoenzyme or occurred upstream of the kinase, we assessed the capacity of genetic activation of PKA to rescue adrenal insufficiency in Senp2 ${ }^{c K O}$ mice by removing the RI $\alpha$ subunit (Prkar1a floxed allele) known to derepress PKA catalytic activity [8, 9, 27]. As expected, 4-week-old Prkar1a $a^{c K O}$ mice developed large adrenals with hyperplastic zF and atrophic zG. Adrenals from Senp2,Prkar1a $a^{d c K O}$ and Senp2 $\mathscr{2}^{c K O}$ mice were similarly reduced in cortical cell number and dysplastic, but in addition, the $d c K O$ showed an atrophic zG (loss of DAB2 staining) due to the antagonistic action of PKA signaling on $\mathrm{zG}$ identity (Figure 3.D. S3C.D.). As a result, in the absence of $\mathrm{NaCl}$ supplementation, Senp2,Prkar1 $a^{d c K O}$ mice died prematurely from salt wasting 


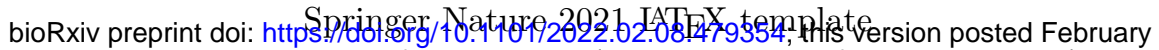
10,2022 . The copyright holder for this preprint (which was not certified by peer review) is the author/funder. All rights reserved. No reuse allowed without permission.

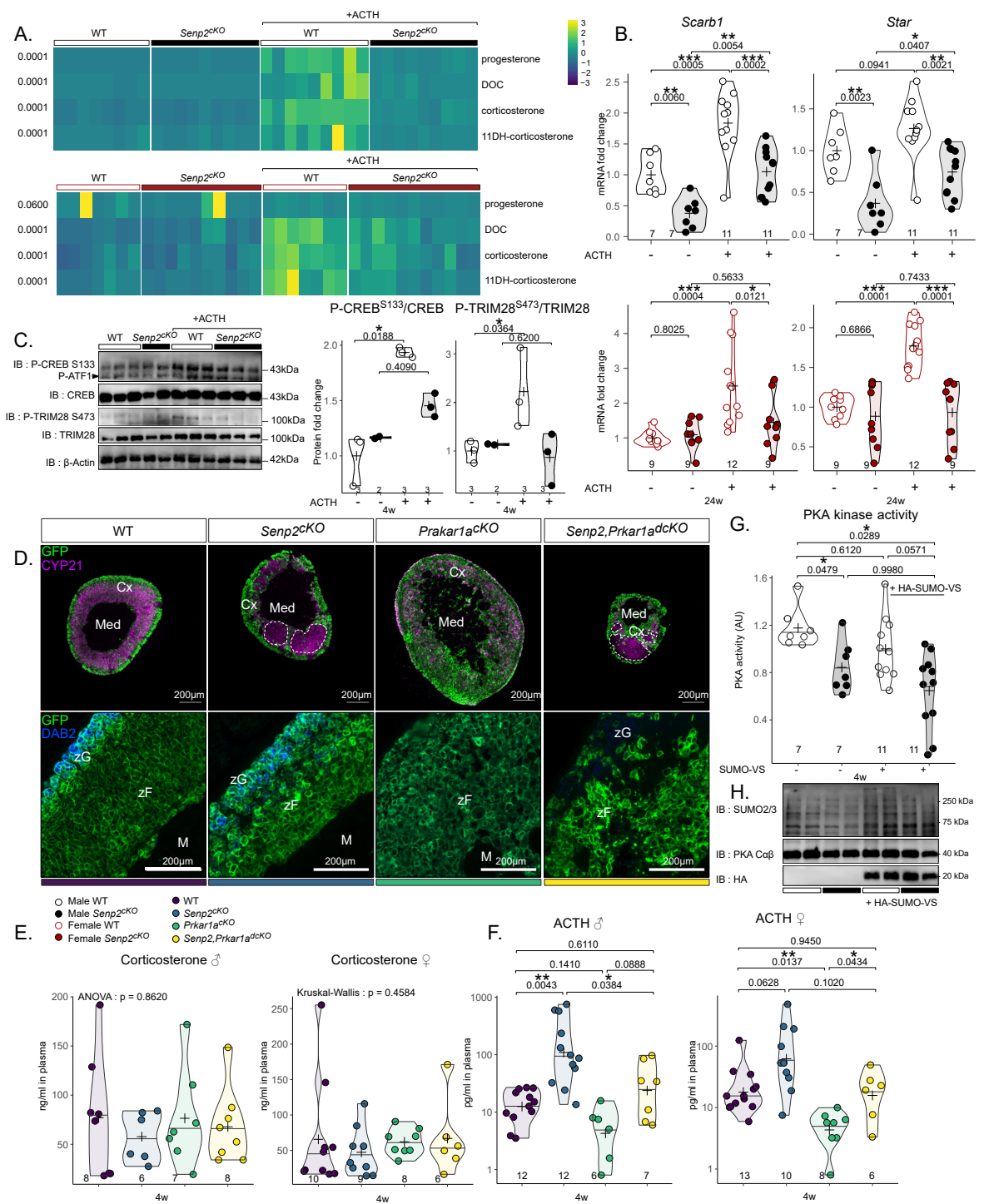

Fig. 3: Senp2 is necessary for proper АCTH response.

A. Heatmap representing the plasmatic concentration of progesterone, DOC, corticosterone and 11-dehydrocorticosterone after treatment with PBS or ACTH for $2 \mathrm{~h}$ determined by LC-MS/MS in WT or Senp2 $2^{c K O} 24$-week-old mice.

B. qPCR analysis of ACTH responsive genes mRNA accumulation in 24-week-old WT and Senp $2^{c K O}$ mice after treatment with PBS or ACTH for $2 \mathrm{~h}$.

C. Western blot analysis of phosphorylated CREB (Ser133) and TRIM28 (Ser473) in 4-week-old mice treated with PBS or ACTH for 30 minutes. Graphs represent phosphorylated form over total form

D. Coimmunofluorescent labelling of GFP (green) with CYP21 (purple) or DAB2 (blue) on WT, Senp $2^{c K O}, \operatorname{Prkar} 1 a^{c K O}$ or double knock-out adrenals.

E. Plasmatic concentration of corticosterone in 4-week-old WT, Senp2 $2^{\text {cKO }}$, Prkar $1 a^{c K O}$ or double knock-out male and female mice

F. Plasmatic concentration of ACTH in 4-week-old WT, Senp2 $2^{c K O}, \operatorname{Prkar1} a^{c K O}$ or double knockout male and female mice

G. PKA kinase activity measurements in WT and Senp2 $2^{c K O} 4$-week-old adrenals in presence or absence of $5 \mu \mathrm{M}$ SUMO vinyl sufone

H. Western blot analysis of global SUMOylation and PKA catalytic subunits protein accumulation 4 -week-old adrenals from WT and Senp $2^{\text {cKO }}$ mice 
bioRxiv preprint doi: httpspringer / fort 10,2022 . The copyright holder for this preprint (which was not certified by peer review) is the author/funder. All rights reserved. No reuse allowed without permission.

SENP2 controls adrenal cortex homeostasis

(Figure S3.E.) due to more general adrenal insufficiency than Senp $2^{c K O}$, which solely suffered from isolated glucocorticoid deficiency. Thus, genetic derepression of PKA was unable to overcome cortical atrophy and dysplasia imparted by Senp2 deficiency. This suggested that consequences of Senp2 loss, including the excess of SUMOylation, had a dominant impact on the $\mathrm{zF}$ homeostasis over PKA constitutive activation. Then, we explored endocrine activity of double KO mice. Although plasma corticosterone dosage showed no differences among the four genotypes, plasma ACTH concentrations were elevated in Senp2 $2^{c K O}$ and plummeted in Prkar1a ${ }^{c K O}$, consistent with the corresponding associated disorders i.e. glucocorticoid deficiency and ACTHindependent glucocorticoid excess, respectively (Figure 3.E.F.). By contrast, Senp2-Prkar1a double ablation restored ACTH levels to control values. This strongly suggested that the lack of Senp2 resulted, among other things, in the repression of PKA catalytic activity that the deletion of one regulatory subunit could partially overcome. Indeed, PKA kinase activity was decreased by $30 \%$ in Senp $2^{c K O}$ adrenal extracts compared to WT without affecting $\mathrm{C} \alpha \beta$ protein levels (Figure 3.G.H.). To test a possible direct repressive effect of SUMOylation, we measured kinase activity in the presence of a mix of SUMO1/2 modified with vinyl sulfone (SUMOs-VS) acting as specific trap and potent inhibitors of SENPs SUMO proteases present in the extracts [28]. Under these conditions enhancing SUMOylation in adrenal extracts, PKA kinase activity was further decreased in Senp $2^{c K O}$, reaching a $50 \%$ inhibition (Figure 3.G.H.). Together, these results present SENP2 as a mandatory actor of proper ACTH response acting most likely by limiting repressive action of SUMOylation on the catalytic activity of the PKA holoenzyme.

\section{Senp2 is necessary for the acquisition of $\mathrm{zF}$ identity}

Based on the blunted response to $\mathrm{ACTH}$, we decided to assess the differentiation status of the $\mathrm{zF}$ in $S e n p 2^{c K O}$ mice. We took advantage of cortical cells' capacity to escape recombination to compare the intensity of differentiation markers in neighbouring cells, differing only by their recombination status. We performed triple staining of GFP, used as a proxy of Senp2 recombination, with DAB2 and AKR1B7 labelling $\mathrm{zG}$ and $\mathrm{zF}$, respectively. We observed a consistent lower AKR1B7 staining intensity in GFP-positive cells, indicating that loss of Senp2 hinders cells from expressing zF markers compared to neighbouring GFP-negative cells (Figure 4.A.B. \& S4.A. for additional example). RT-qPCR analysis revealed increased accumulation of progenitors' markers and increased number of NR2F2-positive capsular cells in males (Figure S4.B.C.) implying a default in cortical cell turnover and/or tending - along with downregulated AKR1B7 expression toward a block of centripetal differentiation. This hypothesis was further supported by an increased proportion of cells coexpressing DAB2 and AKR1B7 in the cortex of Senp $2^{c K O}$ suggesting altered $\mathrm{zG}$ to $\mathrm{zF}$ transdifferentiation (Figure 4.C.). To examine this hypothesis, we performed functional lineagetracing analysis of Senp2-deficient cells using mTmG reporter mice and 
bioRxiv preprint doi: httpspringer / fort 10,2022 . The copyright holder for this preprint (which was not certified by peer review) is the author/funder. All rights reserved. No reuse allowed without permission.

$A S^{\text {Cre }}$ driver [2], which allowed to delete Senp2 in zG cells after birth $\left(A S^{C r e} /+:: S e n p 2^{f l / f l}:: R 26 R^{m T m G / m T m G}\right)$. This Cre driver enabled to assess cortex cellular turnover through the percentage of GFP-stained cells progressing centripetally: complete cortical cell renewal in WT mice taking around 12 weeks in females and 40 weeks in males [8, 29] (Figure 4.D.). In WT females, GFP immunostaining marked the first third of the cortex $(\mathrm{zG}$ and upper $\mathrm{zF}$ ) at 4 weeks of age, whereas $A S^{C r e} /+S e n p 2^{c K O}$ littermates showed GFP staining confined to $\mathrm{zG}$ and rare stripes projecting into the zF. To accelerate lineage tracing, we made the Cre homozygous, which concomitanly deleted Aldosterone Synthase gene $\left(A S^{C r e} / C r e \quad:\right.$ Senp $2^{f l / f l}$ $\left.:: R 26 R^{m T m G / m T m G}\right)$. This breeding strategy enhanced trophic drive through renin-angiotensin signalling, and increased recombination rate leading to fully recombined cortex by 5 weeks of age in females [2]. Lineage marking analysis showed a nearly complete recombination by 4 weeks of age in $A S^{C r e / C r e}$ Senp2 heterozygous adrenals while, once again, $A S^{C r e / C r e} S e n p 2^{c K O}$ showed GFP staining confined to $\mathrm{zG}$ (slightly expanded because of trophic drive in that particular genetic configuration), with few stripes of GFP-positive cells in the zF. A similar phenotype was observed in $A S^{C r e /+} S e n p 2^{c K O}$ at 40 weeks of age with a recombined $\mathrm{zF}$ consisting of scattered stripes of GFP-positive cells (Figure 4.E.) We next quantified AKR1B7 protein accumulation in zF cells

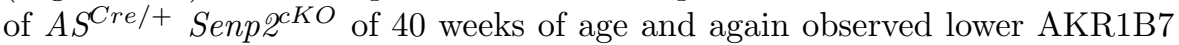
staining in GFP-positive cells (GFP- 95\% CI [6887;7164] AU, GFP+95\% CI [5427;5582] AU) (Figure 4.F.G.). These mice presented no alteration of relative adrenal weight at 24 weeks of age (Figure 4.H.). However, when ACTH responsiveness was assessed over time, plasma corticosterone peaked 2 hours after ACTH treatment in WT, while the response was of lower magnitude in $A S^{C r e /+}$ Senp $2^{c K O}$ and never reached statistical threshold (Figure 4.I.). Remarkably, data from this postnatal Senp2 invalidation mouse model allows to discriminate the effect due to the loss of Senp2 by itself from the impact of hypoplasia. Taken together, our converging models show that deleting Senp2 in the glomerulosa cells prevents their physiological transdifferentiation into zF cells. This lineage blocking point concomitantly select cells that escaped recombination to thrive and let those that cannot, with an incomplete $\mathrm{zF}$ identity, which is sufficient to prevent the adrenal cortex from appropriately responding to ACTH stimulation.

\section{Senp2 deficient cells undergo apoptosis associated with DRP1 phosphorylation}

We next examined the cellular mechanisms underlying the development of zF atrophy in Senp2cKO mice, so we moved our focus to the proliferation/apoptosis balance. The cortical proliferation index determined by scoring the number of Ki67- or BrdU-positive cells ruled out the contribution of a decreased proliferation rate to the hypoplastic phenotype. Instead a trend toward increased cell division in mutant adrenals was observed (Figure S5.A.B.). Nonetheless, cleaved caspase-3 staining showed that the numbers 


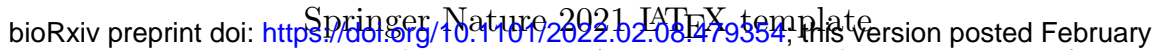
10,2022 . The copyright holder for this preprint (which was not certified by peer review) is the author/funder. All rights reserved. No reuse allowed without permission.

A

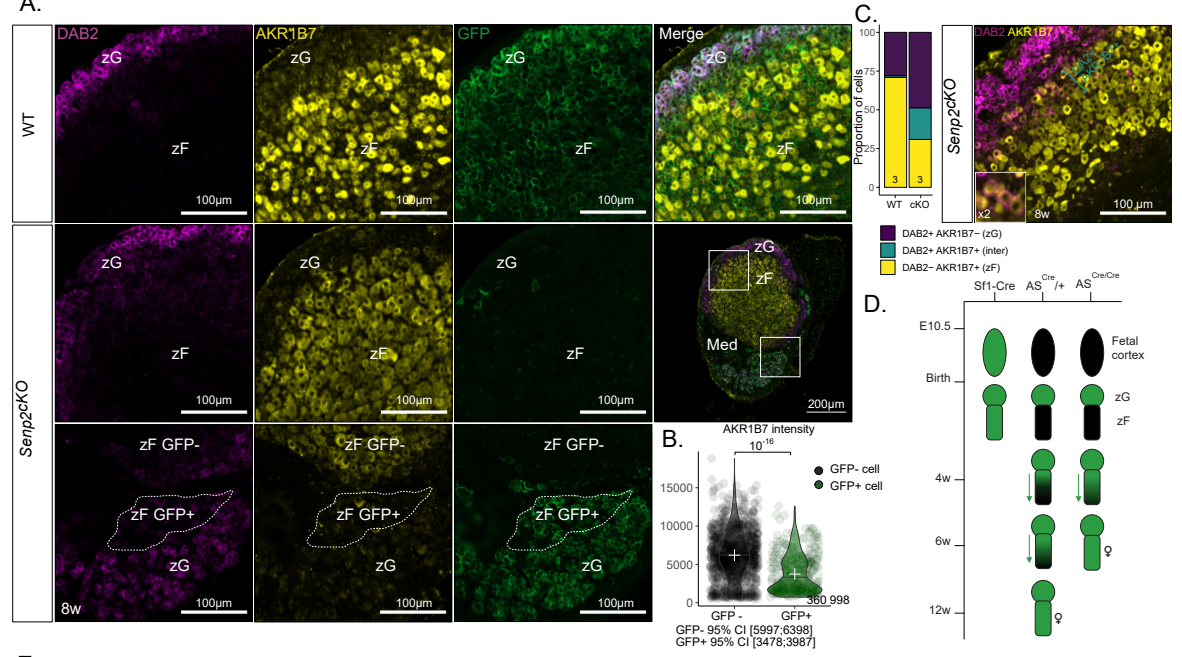

E.

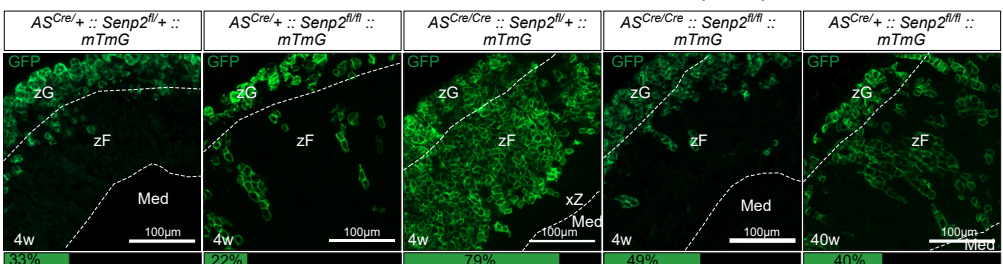

$\mathrm{F}$.

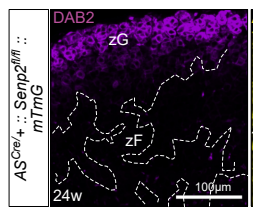

H. Adrenal mass I.

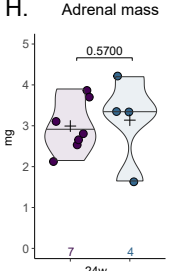

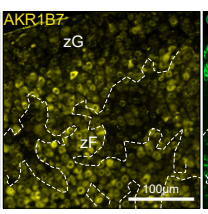

Corticosterone

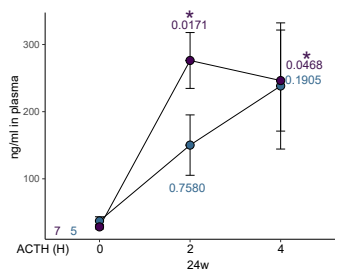

G.

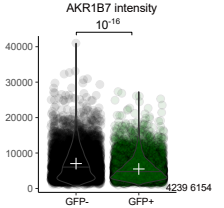

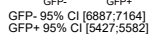

\section{- Female WT}

Female $A S^{C^{\mathrm{rim}} /+}+$ Senp2 2 Ko

Fig. 4: Senp2 ablation prevents proper zF differentiation

A. Coimmunofluorescence labelling of AKR1B7 (yellow), GFP (green) and Disabled2/DAB2 (purple) on 8-week-old WT and Senp $2^{c K O}$ male adrenals

B. Quantification of AKR1B7 intensity in GFP+ and GFP-Senp2 $2^{c K O}$ male adrenal cells

C. Quantification and representative image of cells expressing DAB2 (purple), AKR1B7 (yellow) or both (blue) in WT and Senp $2^{c K O}$ 8-week-old adrenals

D. Scheme representing the differences in recombination between models

E. Immunofluorescence labelling with mean quantification of GFP staining in 4w and 40w adrenals F. Coimmunofluorescence labelling of AKR1B7 (yellow), GFP (green) and Disabled2/DAB2 (purple) on female 24-week-old $A S^{C r e} /+S e n p 2^{c K O}$ adrenals

G. Quantification of AKR1B7 intensity in GFP+ and GFP- 24-week-old $A S^{C r e} /+$ Senp2 $2^{\text {cKO }}$ adrenal cells

H. Mean adrenal mass of 24-week-old female $A S^{C r e} /+$ Senp2 and WT

I. Kinetics of ACTH response of 24 -week-old female $A S^{C r e} /+S e n p 2$ and WT. $P$-values represent difference between samples from the same mice before treatment compared to after 2 hours or after 4 hours of treatment. 


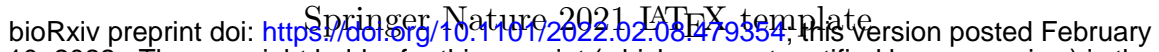
10,2022 . The copyright holder for this preprint (which was not certified by peer review) is the author/funder. All rights reserved. No reuse allowed without permission.

14 SENP2 controls adrenal cortex homeostasis
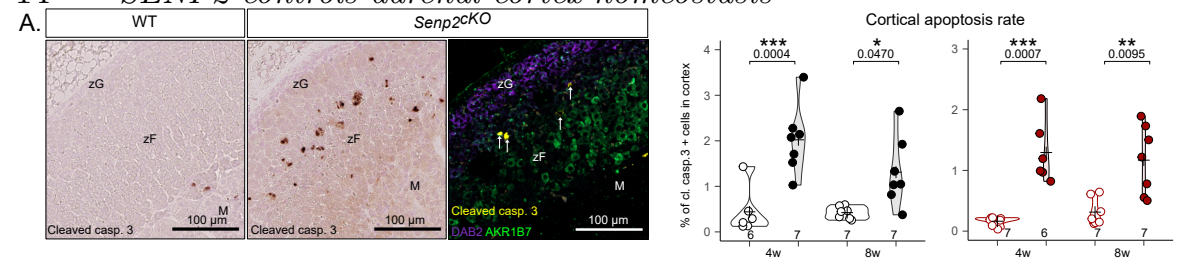

B.

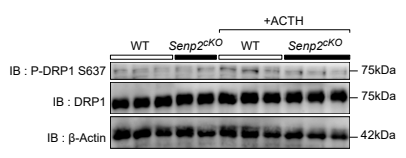

C.
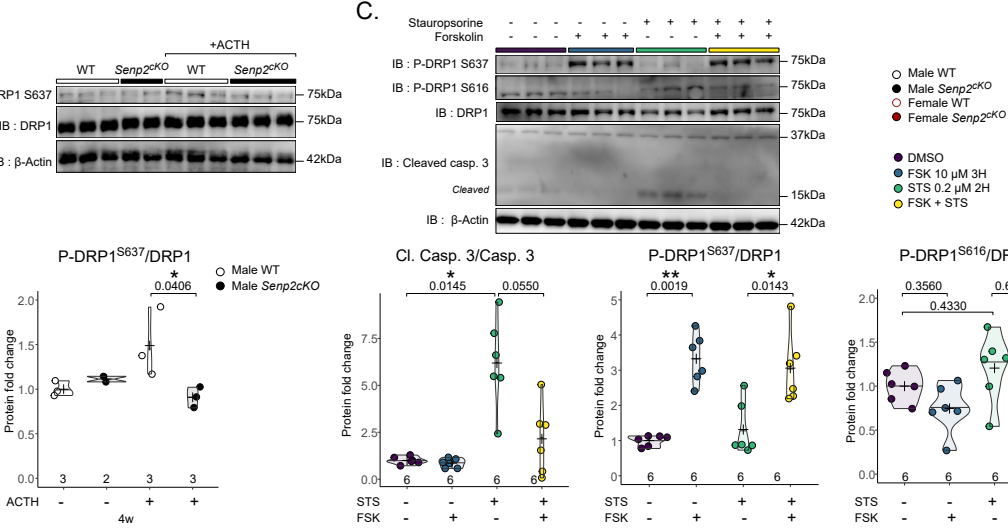

Cl. Casp. 3/Casp. 3

P-DRP1 ${ }^{\text {S637/DRP1 }}$ STS $0.2 \mu \mathrm{MM} 2 \mathrm{H}$
FSK + STS

P-DRP1 ${ }^{\text {S616/DRP1 }}$
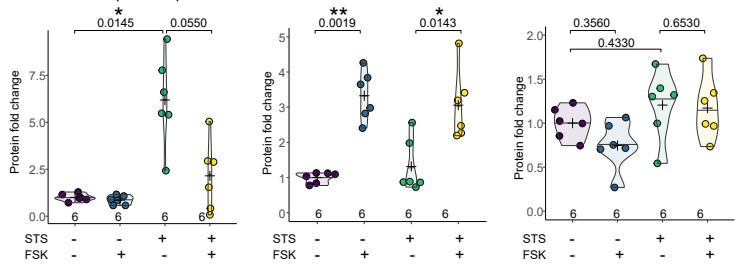

D.

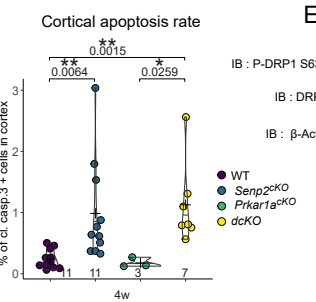

E. WT Senp2 $2^{\text {cKo }}$ Prkar1 ${ }^{\text {cKo }}$ Senp2Prkar1a dcKo P-DRP 1 S637/DRP1

F.

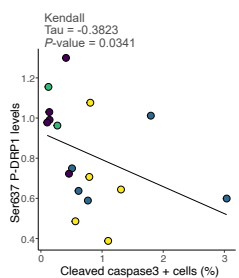

Fig. 5: Senp2 loss triggers apoptosis at the zG-zF boundary

A. Representative image of cleaved caspase-3 immunostaining and immunofluorescence labelling of cleaved caspase-3 (yellow), zG marker Disabled2/DAB2 (purple) and zF marker AKR1B7 (green). Quantification of apoptosis in WT and cKO through measurement of the percentage of cells positive for cleaved caspase 3 at 4 and 8 weeks of age

B. Western blot analysis of S637 phosphorylated and total DRP1 in adrenal after 30 minutes ACTH I.P. treatment of WT and Senp $2^{c K O}$ mice

C. Western blot analysis of phosphorylated and total DRP1 in cells treated with DMSO, Forskolin $(10 \mu \mathrm{M})$ and/or Staurosporine $(0.2 \mu \mathrm{M})$.

D. Quantification of cleaved caspase-3 positive cells in the cortex (E) of WT, Senp2 $2^{c K O}$, Prkar $1 a^{c K O}$ and double knock-out adrenals

E. Western blot analysis of S637 phosphorylated and total DRP1 in the cortex (E) of WT, Senp $2^{c K O}, \operatorname{Prkar} 1 a^{c K O}$ and double knock-out adrenals

F. Correlation plot between Ser637 DRP1 phosphorylation and proportion of cleaved caspase-3 positive cells in the adrenal cortex across genotypes

of cells undergoing apoptosis was, in both sexes, dramatically increased in Senp2 $2^{c K O}$ adrenals at 4 and 8 weeks of age (Figure 5.A.). Physiologically and according to the cortex centripetal cell renewal, the oldest cells are found and die at the corticomedullary junction. However, in the $S e n p \mathscr{2}^{c K O}$ cortex, apoptosis occurred prematurely at the border between the $\mathrm{zG}$ and $\mathrm{zF}$ (Figure 5.A.). 
bioRxiv preprint doi: httpsphinger / No 10,2022 . The copyright holder for this preprint (which was not certified by peer review) is the author/funder. All rights reserved. No reuse allowed without permission.

SENP2 controls adrenal cortex homeostasis

DRP1 (Dynamin related protein 1) is considered the primary driver of mitochondrial fission and mitochondrial-dependant cell death [30] (for review [31]). Phosphorylation of DRP1 on Ser616 activates mitochondrial fission while that on Ser637 prevents the fission. The dysregulation of DRP1 phosphorylations on these two residues will result in imbalanced mitochondrial fission/fusion, a major cause of apoptotic cell death. Phosphorylation on Ser637 particularly raised our attention since the PKA catalysed this posttranslational modification [32]. Besides its participation to inhibition of mitochondrial fission, studies have shown that phosphorylated DRP1-Ser637 promotes steroidogenesis in Leydig cells [33] and corpus luteum [34]. To assess the impact of ACTH/PKA on DRP1 activity in adrenal glands, we performed western blotting of DRP1 and its Ser637 phosphorylated form in WT or Senp2 $2^{c K O}$ adrenal treated with vehicle or ACTH for $30 \mathrm{~min}$. While no difference in total or phosphorylated DRP1 was found in vehicle treated mice, ACTH treatment induced DRP1 Ser637 phosphorylation solely in WT, and in vivo ACTH-induced DRP1 phosphorylation was abolished in Senp2 ${ }^{c K O}$ adrenals (Figure 5.B.).

We then took an in vitro approach to determine whether PKA-induced changes in DRP1 phosphorylation were involved with the apoptotic response of adrenocortical cells. The fasciculata-like ATC7 cells [35] were treated with forskolin (FSK), a pharmacological activator of PKA (through increased cAMP cellular levels), one hour before a 2 hours incubation with the proapoptotic drug staurosporine (STS). As expected, FSK alone resulted in increased Ser637 phosphorylation of DRP1, while STS alone induced caspase-3 cleavage. When combined, FSK limited STS-driven apoptosis as depicted by the reduced accumulation of cleaved caspase-3 (Figure 5.C.). Of note, Ser616 proapoptotic phosphorylation of DRP1 showed a trend to be regulated in the exact opposite way to Ser637. To specifically assess the contribution of DRP1 in STS-induced apoptosis, we pretreated cells with DRP1 specific inhibitor (Mdivi-1) before inducing apoptosis with STS [36]. Similar to FSK, pretreatment with Mdivi-1 resulted in protection against apoptosis as evidenced by reduced accumulation of cleaved caspase-3 (Figure S5.C.). Consistently in vivo, we observed a correlation $(\tau=-0.3823, P$-value $=0.0341)$ between cortical apoptosis rate and DRP1 Ser637 phosphorylation in Senp2, Prkar1a single and double knockouts (Figure 5.D.E.F). Altogether, these results strongly suggest that increased apoptosis seen at the $\mathrm{zG}-\mathrm{zF}$ boundary in $S e n p 2^{c K O}$ adrenals results from a deficient ability of ACTH/PKA signalling to properly phosphorylate DRP1 Ser637.

\section{Senp2 deficiency leads to $\beta$-catenin hyperSUMOylation and mild activation of WNT pathway}

To unravel new SUMOylation-sensitive pathways that could explain further the adrenal insufficiency of mice lacking SUMO protease SENP2, we performed bulk RNA sequencing on four-week-old male and female WT and Senp2 ${ }^{c K O}$. We found 1337 genes to be differentially expressed in male (1115 up and 
bioRxiv preprint doi: httpspringer / fort 10,2022 . The copyright holder for this preprint (which was not certified by peer review) is the author/funder. All rights reserved. No reuse allowed without permission.

222 down) and 1235 in female (960 up and 275 down) (Figure 6.A.B.). Unsupervised clustering and principal component analysis discriminated samples based on genotype but not on sex (Figure S6.A.B.), implying that at 4 weeks of age, sex has a low impact on gene transcription. Since most of the genes were co-regulated in males and females, we chose to focus on these subsets of genes. We performed Gene Ontology (GO) functional enrichment analysis on upregulated or downregulated genes in Senp $2^{c K O}$ adrenals of both sexes. (Figure 6.C.). The top GO terms associated with the upregulated genes were linked to neuron cells and function, which may be due to over representation of medullar chromaffin cells resulting from cortical hypoplasia. Pathways related to steroid processing were enriched in downregulated genes, consistent with the endocrine deficiency phenotype of Senp2 ${ }^{c K O}$ mice.

We performed Get Set Enrichment Analysis (GSEA) on the Kyoto Encyclopedia of Genes and Genomes (KEGG) database and selected only the enriched pathways that were present in both males and females (Figure 6.D.). This confirmed negative enrichment of the gene signature for steroid hormone biosynthesis pathway, in accordance with GO analysis and hormonal insufficiency characterised in Senp ${ }^{c K O}$ mice (Figure 2). Moreover, we found negative enrichment of signatures associated with nucleotide excision repair, aminoacyl tRNA biosynthesis, ribosome, pyrimidine metabolism and spliceosome, indicating that Senp2 gene invalidation in the adrenal cortex altered basic cellular processes known to be regulated by SUMOylation [12]. Interestingly, among the positively enriched pathways, WNT signalling caught our attention as it is mandatory for adrenocortical maintenance and proper zonation $[4,37,38]$ (Figure 6.D.E.)

Based on RNA-Seq analyses and given that SENP2 has first been described as a negative regulator of $\beta$-catenin [39-41], we sought out to see if the WNT/ $\beta$-catenin pathway was altered in Senp2 ${ }^{c K O}$ adrenals. We evaluated the activation of the pathway by running RT-qPCR on its target genes. At 24 weeks of age, we observed a consistent 1.5 fold induction of Axin2, Lef1, Apcdd1 and $C c d c 80$ in the adrenals of $S e n p 2^{c K O}$ females, whereas in mutant males, only $C c d c 80$ was upregulated by about 3 fold (Figure 7.A.). We next carried out immunostaining on adrenal sections that revealed a nuclear localisation of non-phospho (active) $\beta$-catenin specifically in the inner cortex of mutant adrenals regardless of sex (Figure 7.B. top). Co-staining of total $\beta$-catenin with zF marker AKR1B7 confirmed zF identity of these cells, which were also GFP positive hence had been targeted by Cre recombination (Figure 7.B. bottom).

Given that $\beta$-catenin can be SUMOylated by both SUMO1 [42] and SUMO2/3 [43], we hypothesised that it was SUMOylated in the adrenal cortex. We performed immunoprecipitation of both SUMO1 or SUMO2/3 and blotted $\beta$-catenin. We observed a doublet between 120 and $150 \mathrm{kDa}$ for SUMO2/3 consistent with a previous report [43] but no evidence for significant SUMO1 conjugation (Figure 7.C.). To determine if $\beta$-catenin SUMO2/3ylation was affected upon Senp2 deletion, we immunoprecipitated $\beta$-catenin and blotted SUMO2/3. Although we did not see any difference in the amount 
bioRxiv preprint doi: httpspringer / fort 10,2022 . The copyright holder for this preprint (which was not certified by peer review) is the author/funder. All rights reserved. No reuse allowed without permission.

foci showed fewer negative cells and an increased number of cells containing 2 or more $\beta$-catenin/SUMO2/3 dots per nucleus (Figure 7.F.).

Finally, to gain insight into the modulation of the WNT signalling pathway, we extracted expression levels of 48 WNT target genes from RNA-seq data (Figure 7.G.). Among these genes, 31 were upregulated mainly in males Senp $2^{c K O}$ and 7 mainly in females while 10 genes were downregulated in both sexes. In conclusion, loss of SENP2 leads to ectopic nuclear accumulation of $\beta$ catenin in the $\mathrm{zF}$ associated with its increased conjugation to SUMO2/3. This accumulation is correlated with a mild activation of WNT pathway targeting genes in a partially sexually dimorphic pattern.

\section{Discussion}

SUMOylation plays critical roles in the control of genome integrity and expression in eukaryotic cells [44, 45]. As such, alterations of this posttranslational modification have been associated with chronic pathologies such as cancers, degenerative and metabolic diseases [13]. From a physiological perspective, conditional gene invalidation of SUMO enzymes has provided functional evidence that altering the cellular SUMOylation rheostat by installing either a deficit (targeting E2 conjugating enzyme) or an excess (targeting SENP deconjugases), has an impact on critical functions such as cardiac and neuronal physiology [22, 46], intestinal [18] and uterine stem cells homeostasis [47], adipose differentiation and metabolism [17, 48], pancreatic $\beta$-cell secretion [49], macrophages polarisation [50] and immune tolerance [19]. However, how this rheostat can be challenged by or adapted to physiological demand remains unclear. Since in the adrenal cortex, global SUMOylation follows a decreasing gradient from outer zone hosting the progenitor compartment to more differentiated inner cell layers and that Senp2 expression is stimulated by stress through PKA signalling [8], we used adrenal cortex Senp2-deficiency mouse models to figure out the role of SUMOylation in adrenal homeostasis and endocrine function.

The most significant finding from our study is that fetal deletion of Senp2 in adrenal steroidogenic cells causes postnatal hypoplasia limited to the $\mathrm{zF}$ and thus leading to isolated glucocorticoid deficiency. This selective atrophy and associated endocrine deficit result both from a blockage of zonal transdifferentiation preventing the switch from $\mathrm{zG}$ to $\mathrm{zF}$ identity, and from a repression of ACTH responsiveness. This demonstrates that the control of SUMOylation orchestrates the maintenance of cortical homeostasis and stress response. Interestingly, overt corticosterone deficiency is only measurable in males at 4 weeks of age even though ACTH levels are higher at all ages tested in both genders. This implies that a subclinical deficiency is permanently established in the mutants despite setting up compensation. This compensation to maintain physiological plasma glucocorticoid levels, which occurs in both sexes but with delay in males, most likely relies on the emergence of a population of cells that has escaped recombination and helps the mutant 


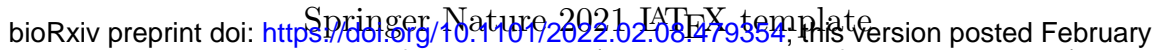
10,2022 . The copyright holder for this preprint (which was not certified by peer review) is the author/funder. All rights reserved. No reuse allowed without permission.

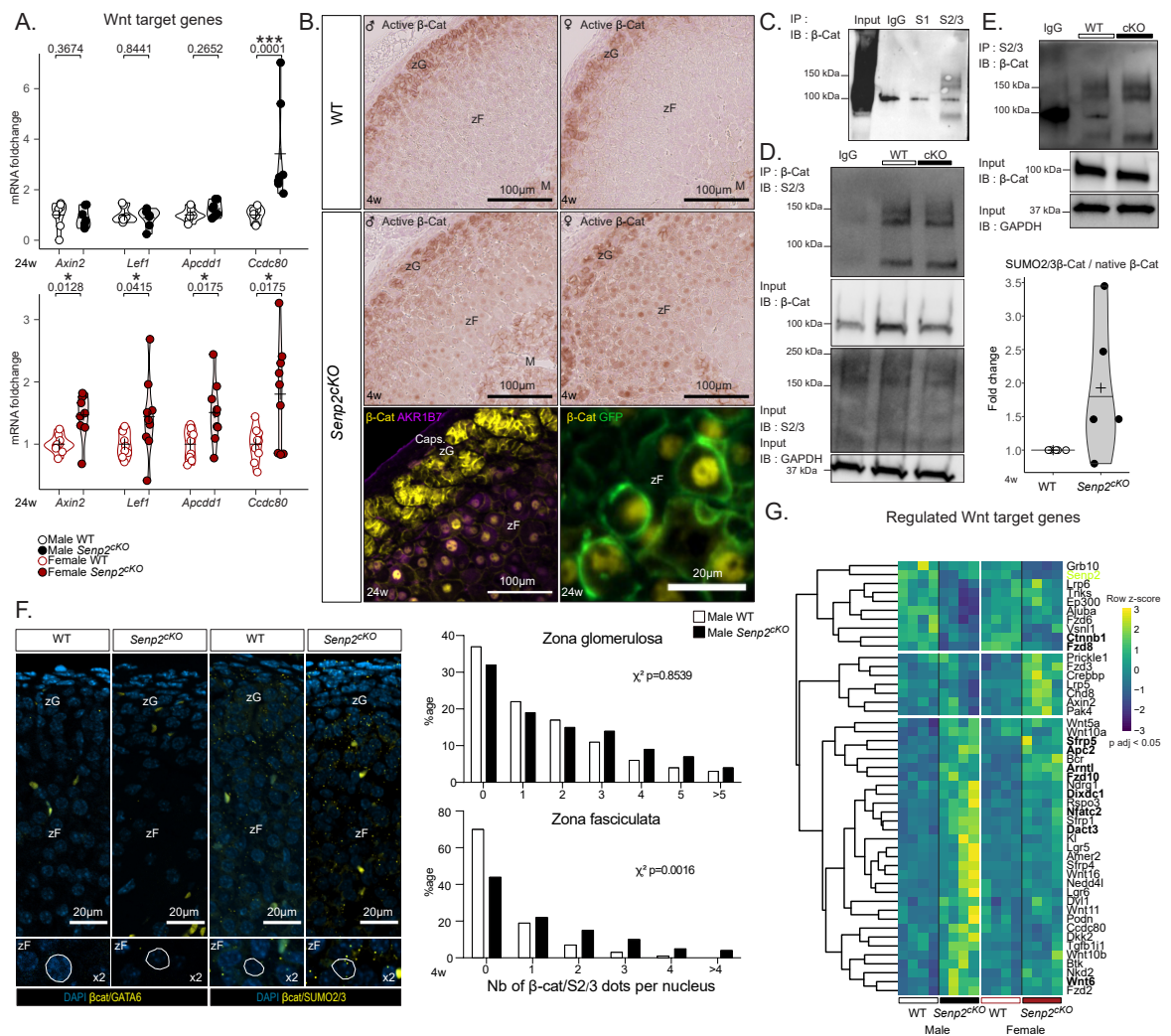

Fig. 7: Senp2 loss promotes $\beta$-catenin SUMOylation and activates the WNT signalling pathway

A. qPCR analysis of $\beta$-catenin target genes Axin2, Lef1, Apcdd1 and Ccdc80 mRNA accumulation in 24-week-old WT and Senp2 $2^{c K O}$ mice.

B. Top : Immunohistochemistry analysis of active (non-phospho) $\beta$-catenin on WT and Senp2 $2^{\text {cKO }}$ male (left) and female (right) adrenals.

Bottom : immunofluorescence staining of $\beta$-catenin (yellow) with zF marker AKR1B7 (purple) and GFP (green).

C. Immunoprecipitation assay depicting the interaction between $\beta$-catenin and SUMO1 or SUMO2/3 in WT adrenals.

D. and E. Immunoprecipitation assay depicting the interaction between $\beta$-catenin and SUMO2/3 in adrenals of 4 -week-old WT and Senp $2^{c K O}$ male mice. Extracts were immunoprecipated with $\beta$-catenin (D) or SUMO2/3 antibodies (E). SUMOylated $\beta$-catenin was quantified relative to its native form.

F. Proximity ligation assay (PLA) of $\beta$-catenin and GATA6 (negative control) or $\beta$-catenin and SUMO2/3 in nuclei of 4-week-old WT and Senp2 ${ }^{c K O}$ male mice's adrenals.

G. Heatmap of dysregulated WNT target genes in Senp2 $2^{c K O}$ male or female adrenals RNA-seq (adjusted $P$-value $<0.05)$. Commonly dysregulated genes in males and females are represented in bold characters. Ca, capsule; zG, zona glomerulosa; $\mathrm{zF}$, zona fasciculata.

cortex to overcome zF atrophy. Indeed, their hypertrophy indicates that they are overreacting to the high levels of circulating ACTH to compensate for the lack of corticosterone due to the dramatic atrophy of the Senp2-deficient zF cell population. 
bioRxiv preprint doi: httpspringer / fort 10,2022 . The copyright holder for this preprint (which was not certified by peer review) is the author/funder. All rights reserved. No reuse allowed without permission.

We hypothesise that steroidogenic progenitor cells, which do not express the Cre recombinase for a still unknown reason, must gain a selective advantage over Senp2-deficient cells, either by being able to proliferate more or by being less prone to death upon differentiation. Similar observations have been made in adrenals following SF-1 loss driven by ASCre [2] or Cyp11a1-Cre [51], where a majority of cells escaped recombination. How cells manage to express a protein but not the Cre while both genes depend on the same promoter is still unknown. One possibility could be methylation of the promoter. For instance, Ins1-Cre transgene is shown to be a poor quality driver to target $\beta$ cells in the pancreas as its expression is silenced by de novo methylation even though Ins1 gene is normally expressed [52]. In any case, the triggering of a compensatory mechanism underlines the absolute necessity of maintaining Senp2 expression (and thus the possibility of reducing SUMOylation) in order to build a functional fasciculata zone and support the individual's ability to adapt to stress.

The fact that Senp2-deficiency preferentially affects the $\mathrm{zF}$ while expressed in all cortical areas [53] can be explained by two non-mutually exclusive mechanisms. First, the zG already harbours high levels of nuclear SUMOylation compared to the $\mathrm{zF}$ [20], therefore the expected increase in SUMOylation conjugates consecutive to lowered deconjugase pools will preferentially affect hypoSUMOylated regions. Moreover, we showed that SENP2 loss alters the PKA/WNT balance toward WNT signalling. The latter being already highly active in the $\mathrm{zG}[4-6]$, it is not surprising to find an altered phenotype only in the $\mathrm{zF}$ where WNT/ $\beta$-catenin signalling is naturally repressed [9]. The second reason is that low SUMOylation seems to be a prerequisite for adequate PKA signalling. Indeed, in our model, ACTH response is blunted and the $\mathrm{zF}$ atrophy phenotype is reminiscent, at least partially, of mouse models lacking ACTH receptor and its co-receptor i.e. $M c r 2 r^{-/-}$or $\mathrm{Mrap}^{-/-}$whole-body knock-outs [54, 55]. Although various mechanisms could be simultaneously affected and remain to be explored, converging pieces of evidence suggest that SENP2 deletiondependant SUMOylation alters PKA responsiveness. Indeed, first our data show that SENP2 deletion decreases overall PKA activity in the adrenal glands and prevents the phosphorylation of specific targets (Ser133CREB, Ser637DRP1, Ser473TRIM28). Secondly, since Senp $2^{c K O}$ phenotype is not rescued by concomitant deletion of PKA regulatory subunit (Prkar1a), it is very likely that SENP2 loss directly affects the PKA catalytic subunits function. This is in line with 1) the presence of conserved K169 lysine in the major subunits (PRKACA and PRKACB) amino acid sequence, predicted as a SUMO consensus motif ( $\psi \mathrm{KxD} / \mathrm{E}$ where $\psi$ is a hydrophobic residue) and 2$)$ the decreased PKA activity caused by SUMO vinyl sulfone derivatives observed in figure 3.G.H. Further studies will assess the SUMOylation of the catalytic subunits and their potential in fine-tuning PKA kinase activity.

SENP2 has first been described as a negative regulator of $\beta$-catenin stability [40] but this effect was independent of SUMOylation. Our model 
bioRxiv preprint doi: httpspringer / fort 10,2022 . The copyright holder for this preprint (which was not certified by peer review) is the author/funder. All rights reserved. No reuse allowed without permission.

showed increased $\beta$-catenin SUMO2/3ylation along with ectopic nuclear $\beta$-catenin localisation associated with a gene signature indicative of the canonical WNT signalling. Similar observations have been reported following direct SUMOy2/3lation of $\beta$-catenin in mammary epithelial cells [43] or SUMOylation of TBL1/TBLR1 that in turn increased chromatin recruitment of $\beta$-catenin and its oncogenic activity in colon cancer [56]. However, the picture is not as clear since $\beta$-catenin SUMO2/3ylation can trigger its degradation in vascular smooth muscle cells [57] or prevent it in mammary epithelial cells [43]. Targeting gain-of-function mutation of $\beta$-catenin in aldosteronesynthase expressing cells caused hyperplasia by blocking glomerulosa cells ability to transdifferentiate into fasciculata cells [3]. However, in contrast with Senp $2^{c K O}$ mice, zF cells never became atrophic in $\beta$-catenin gain-of-function, leading the authors to propose that when physiological transdifferentiation is unachievable, the zF can be maintained by an alternative cellular pathway involving progenitor cells bypassing the $\mathrm{zG}$ state [2]. Here, we report the first occurrence of $\beta$-catenin SUMOylation associated with its nuclear translocation which takes place ectopically in Senp2-deficient zF. This leads to moderate WNT target genes activation and together with blunted PKA activity, impairs acquisition of fasciculata identity. In this context where zGto-zF zonal transdifferentiation is impaired, the deficit in PKA signalling alters the phosphorylation profile of the major mitochondrial fission GTPase, DRP1, leading to premature apoptosis of the neoformed mutant fasciculata cells, reinforcing the atrophy of the zone over time. The block in zonal transdifferentiation induced by $z G$-targeted stabilised $\beta$-catenin has been ascribed to increased rosette formation (the basal cellular organisation of zG cells forming flower-like structures) and/or impaired rosette resolution (the moment when $\mathrm{zG}$ cells exit the rosette to form a single column of cells typical of zF) [58]. Conversely, adrenal cortex lacking Senp2 do not exhibit zG hyperplasia and thus should not display enhanced rosette formation. Our data indicate that mechanisms by which zG undergo resolution during normal homeostatic turnover should be controlled by SUMOylation. Identifying what targets of Senp2-dependent SUMOylation directly contribute to zG resolution and whether this is coupled to $\mathrm{zF}$ transdifferentiation will require extensive studies.

SUMOylation has already proven a role in adrenocortical development with the unSUMOylatable $S F 1^{2 K R / 2 K R}$ model, which results in adrenal cells expressing gonadal markers [21]. In ovaries which share a common fetal origin with adrenals, SUMOylation by E3 SUMO ligase activity of TRIM28 is essential for maintenance of granulosa cell fate at the expense of Sertoli-like identity [59], whereas SENP1 presence in stromal cells is necessary for proper oocyte maturation and ovulation [60]. From a broader perspective, our study belongs to a growing corpus of evidence associating SUMOylation with coordination of differentiation in different tissues and cell types such as white and brown adipose tissue [15, 17, 61], induced pluripotent stem cells [16], or intestine [18]. Seemingly counter-intuitively, the induction 
bioRxiv preprint doi: httpspringer / fort 10,2022 . The copyright holder for this preprint (which was not certified by peer review) is the author/funder. All rights reserved. No reuse allowed without permission.

of the adrenal phenotype of $S e n p 2^{c K O}$ mice does not rely on an overall increase in SUMO conjugates levels but rather on specific overSUMOylation of certain cell populations (Figure S1.I.J.) or substrates belonging to signalling pathways crucial for adrenal homeostasis. These findings are consistent with recent studies exploring the consequences of increased SUMOylation in the uterine stroma (by Senp1 deletion) or decreased SUMOylation (by $U b c 9$ haploinsufficiency) in the intestine of $A p c$ mutant mice that showed strong phenotypes despite any global changes in visible SUMO conjugate levels $[47,62]$. This illustrates the great versatility of this posttranslational modification pathway. Changes in SUMOylation capacity can have specific effects in vivo, especially when targeted steps are catalysed by various members of the same enzymatic family, such as E3 SUMO-ligases or SUMO-specific proteases, which can therefore differ in their substrate specificity. With this in mind, we speculate that specific over-SUMOylated substrates produced in Senp2-deficient adrenals should result from the primary loss of the SUMOprotease. Their SUMOylation could be reinforced by the unrepressed (hypophosphorylated) E3 SUMO-ligase activity of TRIM28 [63, 64], secondary to the blunted ACTH/PKA signalling.

Overall, the present paper demonstrates that preventing deSUMOylation by adrenocortical specific SENP2 ablation induces zF hypoplasia associated with increased premature apoptosis along the lineage conversion $\mathrm{zG}-\mathrm{zF}$ process, ultimately resulting in a blockage of the physiological differentiation process, translating to isolated glucocorticoid deficiency. This is linked to dysregulation of WNT/PKA balance in favour of WNT signalling. This shift highlights the central role of SUMOylation in physiological processes such as differentiation, tissue maintenance, and stress response. Furthermore, our data could broaden the scope of expected impacts of SUMOylation alterations to endocrine pathogenesis. Although diseases association has been made with alterations in SUMO enzymes or substrates, direct causal links to pathologies have very rarely been established $[13,65]$. In conclusion, our work suggests that genetic alterations leading to excessive SUMOylation could provide avenues for exploring new causes of isolated glucocorticoid deficiency.

\section{Methods}

\section{Cell culture}

Adrenocortical tumour cell line 7 (ATC7) cells were established from an adrenal tumor derived from a mouse expressing the Simian Virus 40 large $\mathrm{T}$ (SV40 T) antigen under the control of the aldo-keto reductase $1 \mathrm{~b} 7$ (Akr1b7) gene promoter specific to the adrenal cortex $[35,66]$. Cells were cultured on poly-D-lysine-coated $10 \mathrm{~cm}$ cell culture dishes (MilliporeSigma, Burlington, MA) in a DMEM-F12 medium (Thermo Fisher Scientific, Waltham, MA) at $37^{\circ} \mathrm{C}$ in the presence of $5 \% \mathrm{CO} 2$, insulin $(10 \mathrm{mg} / \mathrm{mL})$, transferrin $(5.5$ $\mathrm{mg} / \mathrm{mL})$, selenium $(6.7 \mathrm{ng} / \mathrm{mL})$ (Thermo Fisher Scientific), L-glutamine (2 $\mathrm{mM})$, penicillin $0.1 \mathrm{U} / \mathrm{mL})$, streptomycin $(0.1 \mathrm{mg} / \mathrm{mL}), 2.5 \%$ horse serum, 
bioRxiv preprint doi: httpsphinger / No 10,2022 . The copyright holder for this preprint (which was not certified by peer review) is the author/funder. All rights reserved. No reuse allowed without permission.

and $2.5 \%$ fetal calf serum. Cells were seeded in 12-well plates and cultures to subconfluence and then starved by replacing medium by serum-free medium the day before the addition of forskolin (Sigma-Aldrich), staurosporine (SigmaAldrich) or Mdivi-1 (Merck) at the times and concentrations indicated in the figure's legends.

\section{Mice}

Mice bred in-house and maintained on a mixed sv129-C57Bl/6 genetic background were housed on a 12-hour light/12-hour dark cycle (lights on at 7:00 am). Mice were fed normal, commercial rodent chow and provided with water ad libitum. After weaning, mice were kept in siblings with a maximum of 4 animals per cage.

\section{Hormonal measurements}

Mice were killed by decapitation around 8:30 am and blood was collected in vacuum blood collection tubes (VF-053STK, Terumo). For ACTH treatments mice were injected intraperitoneally with $0.05 \mathrm{mg} / 30 \mathrm{~g}$ Synacthene $(0.25$ $\mathrm{mg} / \mathrm{mL}$, Novartis, Basel, Switzerland) 2 hours or 30 minutes prior the euthanasia. ACTH response kinetics in Figure4.I., was done with collection of the blood from the tail of the mice at 8 am, 10 am and $12 \mathrm{pm}$.

Corticosterone was measured from serum with ELISA kit (AR E-8100, LDN), ACTH was measured with Milliplex Map Kit (MPTMAG-49K, Millipore) and other steroids were measured by LC-MS/MS [67].

\section{Histology and Proximity ligation assay}

Adrenals were fixed in $4 \%$ PFA for 6 hours and embedded in paraffin. 5um sections were deparaffinised and processed for H\&E. For immunohistochemistry or immunofluorescence, deparaffinised slides were submerged in antigen retrieval buffer and microwaved for 8 minutes. After being rinsed with $1 \mathrm{X}$ PBS, they were blocked for an hour with $2.5 \%$ horse serum (Vector) and incubated overnight at $4^{\circ} \mathrm{C}$ with primary antibody. After rinsing, they were incubated with ImmPRESS polymer for 30 minutes at room temperature. HRP activity was detected with NOVAred (Vector) or Alexafluor (Thermo Fisher). Primary antibodies are listed in supplementary table.

For PLA, blocked slides were incubated overnight at $4^{\circ} \mathrm{C}$ with indicated antibodies followed by Duolink in situ PLA (Sigma-Aldrich) anti-mouse (minus) and anti-rabbit (plus) probes and detection reagents according to manufacturer's instructions.

Images were acquired with Zeiss Axioscan Z1 or Zeiss Imager M2 and analysed with QuPath software [68].

\section{RT-qPCR}

Adrenal glands were removed, flash frozen on dry ice, and RNA was extracted using RNeasy micro kit from QIAGEN. After reverse transcription, PCR reaction was conducted using SYBR qPCR Premix Ex Taq II Tli RNase $\mathrm{H}+($ TAKRR820W, Takara). Primer pairs are listed in supplementary table 1.

\section{RNA-Seq}


bioRxiv preprint doi: httpspringer / fort 10,2022 . The copyright holder for this preprint (which was not certified by peer review) is the author/funder. All rights reserved. No reuse allowed without permission.

\section{4}

SENP2 controls adrenal cortex homeostasis

For each sex, adrenal gene expression profiles for four 4-week-old Sf1-Cre/+ $:: S e n p 2^{f l / f l}$ and four WT littermates were analysed using RNA-seq. RNAsequencing, library generation and differential expression genes analysis were performed by the GenomEast platform (IGBMC, Illkirch, France).

Image analysis and base calling were performed using RTA 2.7.3 and bcl2fastq 2.17.1.14. Adapter dimer reads were removed using DimerRemover Reads were mapped onto the mm10 assembly of Mus musculus genome using STAR version 2.5.3a. Gene expression quantification was performed from uniquely aligned reads using htseq-count version 0.6.1p1. Read counts have been normalised across samples with the median-of-ratios method proposed by Anders and Huber. Differential expression have been implemented using the Bioconductor package DESeq2 version 1.16.1. Raw and processed data have been deposited in NCBI's GEO database (GSE193480).

Gene Set Enrichement Analysis was performed using the GSEA software [69] and plotted using the replotGSEA function from the Rtoolbox package (https://github.com/PeeperLab/Rtoolbox). Gene ontology analysis was performed using g:Profiler [70]. Data visualisation was carried out using $\mathrm{R}$ software (v4.1.0) [71], Pheatmap package was used for heatmaps, Vennerable for Euler diagrams and ggplot2 for plots. PCA analysis was produced on read counts matrix using prcomp function from the stats package and plotted using ggplot2.

\section{Western blot and immunoprecipitation}

Proteins were extracted from snap frozen adrenals in RIPA buffer (TRIS $25 \mathrm{mM}$, EDTA $1 \mathrm{mM}, \mathrm{MgCl}_{2} 5 \mathrm{mM}$, NP40 1\%, glycerol 10\%, NaCl $150 \mathrm{mM}$ supplemented extemporaneously with phosphatase inhibitors ( $1 \mathrm{mM} \mathrm{Na}_{3} \mathrm{VO}_{4}$, $0.5 \mathrm{mM} \mathrm{NaF}$ ), protease inhibitors (Roche, Basel, Switzerland), and SUMO proteases inhibitor N-ethylmaleimide (MilliporeSigma) $(3.13 \mathrm{mg} / \mathrm{mL})$.

For western blot, thirty $\mathrm{ug}$ of total denatured proteins were loaded on $10 \%$ SDS-page gel, transferred on nitrocellulose and detected with primary antibodies (Supplementary table 2). Signals were quantified with ChemiDoc MP Imaging System camera system (Bio-Rad) and Image Lab software (BioRad). Expression of phosphorylated or SUMOylated proteins was normalised to the expression of the corresponding unmodified protein.

Immunoprecipitation was carried out using Automag Solution (AdemTech). $500-1000 \mu g$ of total proteins were precleared with $50 \mu \mathrm{L}$ of beads for 30 minutes at room temperature. $10 \mu \mathrm{L}$ of antibodies (Supplementary table 2) were crosslinked with $50 \mu \mathrm{L}$ of beads in $20 \mathrm{mM}$ DMP for 30 minutes. Precleared samples were immunoprecipitated with crosslinked antibodies for 60 minutes at room temperature, washed thrice in RIPA buffer and eluted with $50 \mu \mathrm{L}$ of $50 \mathrm{mM}$ glycine $\mathrm{pH}$. $\mathrm{pH}$ was brought back to neutral with $1 \mu \mathrm{L}$ of TRIS buffer pH9 and samples were denatured in Laemmli buffer (Bio-Rad) at $95^{\circ} \mathrm{C}$ for 5 minutes and loaded for SDS-PAGE.

\section{PKA activity}

Proteins were extracted from snap frozen adrenals in lysis buffer (MOPS 20 mM, Betaglycerol-phosphate 50 mM, NP40 1\%, DTT 1 mM, EDTA 2 mM, 
bioRxiv preprint doi: httpsphinger / No 10,2022 . The copyright holder for this preprint (which was not certified by peer review) is the author/funder. All rights reserved. No reuse allowed without permission.

EGTA $5 \mathrm{mM}$ supplemented extemporaneously with phosphatase inhibitors (1 $\mathrm{mM} \mathrm{Na} \mathrm{VO}_{4}, 50 \mathrm{mM} \mathrm{NaF}$ ), protease inhibitors (Roche, Basel, Switzerland). HA-SUMO vinyl sulfone (R\&D Systems, Minneapolis, MN) was added for the SUMO-VS condition to the concentration of $5 \mu \mathrm{M}$ for both SUMO1 and SUMO2.

$10 \mu \mathrm{g}$ of protein from 4-week-old adrenals were used for measurement with PKA kinase activity kit (ab139435, Abcam).

\section{Statistics}

Statistics were conducted using $\mathrm{R}$ language [71] and sumo package (https://github.com/Damien-Dufour/sumo). Normality of populations distribution was assessed with Shapiro \& Wilk test for $\mathrm{n} \in[7,5000]$ or otherwise Kolmogorof- Smirnov normality test.

If data followed a normal distribution, homoscedasticity was estimated with a Barlett test. To compare two populations, unpaired, two tailed t-test was used for normally distributed data with the same variance, Mann-Whitney for non normal distributions and Welch t-test for normally distributed data but with different variances. To compare three or more distributions,

- One way ANOVA for normally distributed samples with pairwise multiple t.tests

- Kruskal-Wallis for non normally distributed samples with planned comparisons using Dunn's test to determine the genotype effect or the treatment effect

Crosses on the violin plots represent the mean and lines represent the median. Error bars in barplot represent the SD unless otherwise stated. The number of samples per condition is indicated at the bottom of each plot. Corticosterone response to ACTH in Figure4.I. was analysed with paired 2 way ANOVA to compare the effect of treatment for each genotype.

\section{Ethical approval declarations}

Mouse experiments were conducted according to French and European directives for the use and care of animals for research purposes and were approved by the Comité d'Éthique pour l'Expérimentation Animale en Auvergne (project agreement \#21152-2019061912052883), C2EA-02, at Institut National de Recherche pour l'Agriculture, l'Alimentation et l'Environnement, Research Centre Clermont-Theix, France (C2E2A).

Data availability. Sequencing data have been deposited in GEO with the accession code GSE193480

\section{Code availability.}

\section{Supplementary information.}

\section{References}

[1] King, P., Paul, A. \& Laufer, E. Shh signaling regulates adrenocortical development and identifies progenitors of steroidogenic lineages. 
bioRxiv preprint doi: httpsphinger / No

10,2022 . The copyright holder for this preprint (which was not certified by peer review) is the author/funder. All rights reserved. No reuse allowed without permission.

Proceedings of the National Academy of Sciences 106 (50), 21185-21190 (2009). https://doi.org/10.1073/pnas.0909471106 .

[2] Freedman, B. et al. Adrenocortical zonation results from lineage conversion of differentiated zona glomerulosa cells. Developmental Cell 26 (6), 666-673 (2013). https://doi.org/10.1016/j.devcel.2013.07.016 .

[3] Pignatti, E. et al. Beta-catenin causes adrenal hyperplasia by blocking zonal transdifferentiation. Cell Reports 31 (3), 107524 (2020). https: //doi.org/10.1016/j.celrep.2020.107524 .

[4] Berthon, A., Martinez, A., Bertherat, J. \& Val, P. Wnt/ß-catenin signalling in adrenal physiology and tumour development. Molecular and Cellular Endocrinology 351 (1), 87-95 (2012). https://doi.org/10.1016/ j.mce.2011.09.009 .

[5] Berthon, A. et al. Constitutive $\beta$-catenin activation induces adrenal hyperplasia and promotes adrenal cancer development. Human Molecular Genetics 19 (8), 1561-1576 (2010). https://doi.org/10.1093/hmg/ddq029

[6] Walczak, E. M. et al. Wnt signaling inhibits adrenal steroidogenesis by cell-autonomous and non-cell-autonomous mechanisms. Molecular Endocrinology 28 (9), 1471-1486 (2014). https://doi.org/10.1210/me. 2014-1060 .

[7] Novoselova, T. V. et al. Acth signalling and adrenal development: lessons from mouse models. Endocrine Connections 8 (7), R122-R130 (2019). https://doi.org/10.1530/EC-19-0190 .

[8] Dumontet, T. et al. Pka signaling drives reticularis differentiation and sexually dimorphic adrenal cortex renewal. JCI Insight 3 (2) (2018). URL https://insight.jci.org/articles/view/98394. https://doi.org/10.1172/jci. insight.98394.

[9] Drelon, C. et al. Pka inhibits wnt signalling in adrenal cortex zonation and prevents malignant tumour development. Nature Communications $\mathbf{7}$, 12751 (2016). https://doi.org/10.1038/ncomms12751 .

[10] Mathieu, M. et al. Steroidogenic differentiation and pka signaling are programmed by histone methyltransferase ezh2 in the adrenal cortex. Proceedings of the National Academy of Sciences 115 (52), E12265-E12274 (2018). https://doi.org/10.1073/pnas.1809185115 .

[11] Minguez, P. et al. Deciphering a global network of functionally associated post-translational modifications. Molecular Systems Biology 8 (1), 599 (2012). https://doi.org/10.1038/msb.2012.31 . 


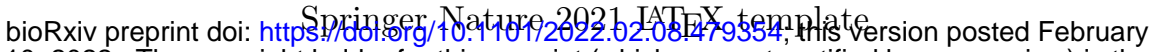
10,2022 . The copyright holder for this preprint (which was not certified by peer review) is the author/funder. All rights reserved. No reuse allowed without permission.

[12] Wilson, V. G. SUMO Regulation of Cellular Processes Vol. 963 of Advances in Experimental Medicine and Biology (Springer International Publishing, 2017). URL http://link.springer.com/10.1007/ 978-3-319-50044-7.

[13] Chang, H.-M. \& Yeh, E. T. H. Sumo: From bench to bedside. Physiological Reviews 100 (4), 1599-1619 (2020). https://doi.org/10.1152/physrev. 00025.2019 .

[14] Talamillo, A. et al. The role of sumoylation during development. Biochemical Society Transactions 48 (2), 463-478 (2020). https://doi. org/10.1042/BST20190390 .

[15] Chung, S. S. et al. Control of adipogenesis by the sumo-specific protease senp2. Molecular and Cellular Biology 30 (9), 2135-2146 (2010). https: //doi.org/10.1128/MCB.00852-09 .

[16] Cossec, J.-C. et al. Sumo safeguards somatic and pluripotent cell identities by enforcing distinct chromatin states. Cell Stem Cell 23 (5), 742-757.e8 (2018). https://doi.org/10.1016/j.stem.2018.10.001 .

[17] Liang, Q. et al. Senp2 suppresses necdin expression to promote brown adipocyte differentiation. Cell Reports 28 (8), 2004-2011.e4 (2019). https: //doi.org/10.1016/j.celrep.2019.07.083 .

[18] Demarque, M. D. et al. Sumoylation by ubc9 regulates the stem cell compartment and structure and function of the intestinal epithelium in mice. Gastroenterology 140 (1), 286-296 (2011). https://doi.org/10.1053/ j.gastro.2010.10.002 .

[19] Ding, X. et al. Protein sumoylation is required for regulatory t cell expansion and function. Cell Reports 16 (4), 1055-1066 (2016). https: //doi.org/10.1016/j.celrep.2016.06.056 .

[20] Dumontet, T. et al. Hormonal and spatial control of sumoylation in the human and mouse adrenal cortex. The FASEB Journal 33 (9), 10218-10230 (2019). https://doi.org/10.1096/fj.201900557R .

[21] Lee, F. et al. Eliminating sf-1 (nr5a1) sumoylation in vivo results in ectopic hedgehog signaling and disruption of endocrine development. Developmental Cell 21 (2), 315-327 (2011). https://doi.org/10.1016/j. devcel.2011.06.028 .

[22] Qi, Y. et al. Hyper-sumoylation of the kv7 potassium channel diminishes the m-current leading to seizures and sudden death. Neuron 83 (5), 1159-1171 (2014). https://doi.org/10.1016/j.neuron.2014.07.042 . 
bioRxiv preprint doi: httpsphinger / No

10,2022 . The copyright holder for this preprint (which was not certified by peer review) is the author/funder. All rights reserved. No reuse allowed without permission.

28 SENP2 controls adrenal cortex homeostasis

[23] Bingham, N. C., Verma-Kurvari, S., Parada, L. F. \& Parker, K. L. Development of a steroidogenic factor 1/cre transgenic mouse line. genesis 44 (9), 419-424 (2006). https://doi.org/10.1002/dvg.20231 .

[24] Muzumdar, M. D., Tasic, B., Miyamichi, K., Li, L. \& Luo, L. A global double-fluorescent cre reporter mouse. genesis 45 (9), 593-605 (2007). https://doi.org/10.1002/dvg.20335 .

[25] Levasseur, A., Dumontet, T. \& Martinez, A. "sexual dimorphism in adrenal gland development and tumorigenesis". Current Opinion in Endocrine and Metabolic Research 8, 60-65 (2019). https://doi.org/10. 1016/j.coemr.2019.07.008 .

[26] Lyraki, R. \& Schedl, A. The sexually dimorphic adrenal cortex: Implications for adrenal disease. International Journal of Molecular Sciences 22 (9), 4889 (2021). https://doi.org/10.3390/ijms22094889 .

[27] Sahut-Barnola, I. et al. Cushing's syndrome and fetal features resurgence in adrenal cortex-specific prkarla knockout mice. PLoS Genetics 6 (6), e1000980 (2010). https://doi.org/10.1371/journal.pgen.1000980 .

[28] Kunz, K., Müller, S. \& Mendler, L. Assays of SUMO protease/isopeptidase activity and function in mammalian cells and tissues, Vol. 618, 389-410 (Elsevier, 2019). URL https://linkinghub.elsevier.com/retrieve/pii/ S0076687919300060.

[29] Grabek, A. et al. The adult adrenal cortex undergoes rapid tissue renewal in a sex-specific manner. Cell Stem Cell 25 (2), 290-296.e2 (2019). https: //doi.org/10.1016/j.stem.2019.04.012 .

[30] Frank, S. et al. The role of dynamin-related protein 1, a mediator of mitochondrial fission, in apoptosis. Developmental Cell 1 (4), 515-525 (2001). https://doi.org/10.1016/S1534-5807(01)00055-7 .

[31] Sabouny, R. \& Shutt, T. E. Reciprocal regulation of mitochondrial fission and fusion. Trends in Biochemical Sciences 45 (7), 564-577 (2020). https: //doi.org/10.1016/j.tibs.2020.03.009 .

[32] Chang, C.-R. \& Blackstone, C. Cyclic amp-dependent protein kinase phosphorylation of drp1 regulates its gtpase activity and mitochondrial morphology. Journal of Biological Chemistry 282 (30), 21583-21587 (2007). https://doi.org/10.1074/jbc.C700083200 .

[33] Park, J.-E. et al. Drp1 phosphorylation is indispensable for steroidogenesis in leydig cells. Endocrinology 160 (4), 729-743 (2019). https://doi.org/ 10.1210/en.2019-00029 . 
bioRxiv preprint doi: httpsphinger / No 10,2022 . The copyright holder for this preprint (which was not certified by peer review) is the author/funder. All rights reserved. No reuse allowed without permission.

[34] Plewes, M. R. et al. Luteinizing hormone regulates the phosphorylation and localization of the mitochondrial effector dynamin-related protein1 (drp1) and steroidogenesis in the bovine corpus luteum. The FASEB Journal fj.201902958R (2020). https://doi.org/10.1096/fj.201902958R .

[35] Ragazzon, B. et al. Adrenocorticotropin-dependent changes in sf-1/dax1 ratio influence steroidogenic genes expression in a novel model of glucocorticoid-producing adrenocortical cell lines derived from targeted tumorigenesis. Endocrinology 147 (4), 1805-1818 (2006). https://doi. org/10.1210/en.2005-1279 .

[36] Manczak, M., Kandimalla, R., Yin, X. \& Reddy, P. H. Mitochondrial division inhibitor 1 reduces dynamin-related protein 1 and mitochondrial fission activity. Human Molecular Genetics 28 (2), 177-199 (2019). https: //doi.org/10.1093/hmg/ddy335 .

[37] Kim, A. C. et al. Targeted disruption of -catenin in sf1-expressing cells impairs development and maintenance of the adrenal cortex. Development 135 (15), 2593-2602 (2008). https://doi.org/10.1242/dev.021493 .

[38] Little, D. W., Dumontet, T., LaPensee, C. R. \& Hammer, G. D. $\beta$-catenin in adrenal zonation and disease. Molecular and Cellular Endocrinology 522, 111120 (2021). https://doi.org/10.1016/j.mce.2020.111120 .

[39] Kadoya, T. et al. Inhibition of wnt signaling pathway by a novel axinbinding protein. Journal of Biological Chemistry 275 (47), 37030-37037 (2000). https://doi.org/10.1074/jbc.M005984200 .

[40] Nishida, T., Kaneko, F., Kitagawa, M. \& Yasuda, H. Characterization of a novel mammalian sumo-1/smt3-specific isopeptidase, a homologue of rat axam, which is an axin-binding protein promoting $\beta$-catenin degradation. Journal of Biological Chemistry 276 (42), 39060-39066 (2001). https: //doi.org/10.1074/jbc.M103955200 .

[41] Kadoya, T. et al. Desumoylation activity of axam, a novel axin-binding protein, is involved in downregulation of $\beta$-catenin. Molecular and Cellular Biology 22 (11), 3803-3819 (2002). https://doi.org/10.1128/MCB.22.11. 3803-3819.2002 .

[42] Huang, H.-J. et al. $\beta$-catenin sumoylation is involved in the dysregulated proliferation of myeloma cells. American Journal of Cancer Research 5 (1), 309-320 (2015) .

[43] Karami, S. et al. Novel sumo-protease senp7s regulates $\beta$-catenin signaling and mammary epithelial cell transformation. Scientific Reports 7, 46477 (2017). https://doi.org/10.1038/srep46477 . 
bioRxiv preprint doi: httpsphinger / No

10,2022 . The copyright holder for this preprint (which was not certified by peer review) is the author/funder. All rights reserved. No reuse allowed without permission.

[44] Zhao, X. Sumo-mediated regulation of nuclear functions and signaling processes. Molecular Cell 71 (3), 409-418 (2018). https://doi.org/10. 1016/j.molcel.2018.07.027 .

[45] Boulanger, M., Chakraborty, M., Tempé, D., Piechaczyk, M. \& Bossis, G. Sumo and transcriptional regulation: The lessons of large-scale proteomic, modifomic and genomic studies. Molecules 26 (4), 828 (2021). https: //doi.org/10.3390/molecules26040828 .

[46] Fu, J. et al. Disruption of sumo-specific protease 2 induces mitochondria mediated neurodegeneration. PLoS Genetics 10 (10), e1004579 (2014). https://doi.org/10.1371/journal.pgen.1004579 .

[47] Yin, M. et al. Cd34+klf4+ stromal stem cells contribute to endometrial regeneration and repair. Cell Reports 27 (9), 2709-2724.e3 (2019). https: //doi.org/10.1016/j.celrep.2019.04.088 .

[48] Zheng, Q. et al. Senp2 regulates adipose lipid storage by de-sumoylation of setdb 9 (2018).

[49] Lin, H. et al. $\beta$-cell knockout of senp1 reduces responses to incretins and worsens oral glucose tolerance in high-fat diet-fed mice. Diabetes 70 (11), 2626-2638 (2021). https://doi.org/10.2337/db20-1235 .

[50] Wang, F. et al. Loss of ubiquitin-conjugating enzyme e2 (ubc9) in macrophages exacerbates multiple low-dose streptozotocin-induced diabetes by attenuating $\mathrm{m} 2$ macrophage polarization. Cell Death 8 Disease 10 (12), 892 (2019). https://doi.org/10.1038/s41419-019-2130-z .

[51] Buaas, F. W., Gardiner, J. R., Clayton, S., Val, P. \& Swain, A. In vivo evidence for the crucial role of sf1 in steroid-producing cells of the testis, ovary and adrenal gland. Development 139 (24), 4561-4570 (2012). https: //doi.org/10.1242/dev.087247 .

[52] Mosleh, E. et al. Ins1-cre and ins1-creer gene replacement alleles are susceptible to silencing by dna hypermethylation. Endocrinology 161 (8), bqaa054 (2020). https://doi.org/10.1210/endocr/bqaa054 .

[53] Lopez, J. P. et al. Single-cell molecular profiling of all three components of the hpa axis reveals adrenal abcb1 as a regulator of stress adaptation. Science Advances 7 (5), eabe4497 (2021). https://doi.org/10.1126/sciadv. abe4497 .

[54] Chida, D. et al. Melanocortin 2 receptor is required for adrenal gland development, steroidogenesis, and neonatal gluconeogenesis. Proceedings of the National Academy of Sciences 104 (46), 18205-18210 (2007). https: //doi.org/10.1073/pnas.0706953104. 
bioRxiv preprint doi: httpsphinger / No 10,2022 . The copyright holder for this preprint (which was not certified by peer review) is the author/funder. All rights reserved. No reuse allowed without permission.

[55] Novoselova, T. V. et al. Mrap deficiency impairs adrenal progenitor cell differentiation and gland zonation. The FASEB Journal 32 (11), 6186-6196 (2018). https://doi.org/10.1096/fj.201701274RR .

[56] Choi, H.-K. et al. Reversible sumoylation of tbl1-tblr1 regulates $\beta$-cateninmediated wnt signaling. Molecular Cell 43 (2), 203-216 (2011). https: //doi.org/10.1016/j.molcel.2011.05.027 .

[57] Cai, Z. et al. Redox-sensitive enzyme senp3 mediates vascular remodeling via de-sumoylation of $\beta$-catenin and regulation of its stability. EBioMedicine 67, 103386 (2021). https://doi.org/10.1016/j.ebiom.2021. 103386 .

[58] Leng, S. et al. $\beta$-catenin and fgfr2 regulate postnatal rosette-based adrenocortical morphogenesis. Nature Communications 11 (1), 1680 (2020). https://doi.org/10.1038/s41467-020-15332-7 .

[59] Rossitto, M. et al. Trim28-dependent sumoylation protects the adult ovary from the male pathway. biorxiv (2021). URL http://biorxiv.org/ lookup/doi/10.1101/2021.03.24.436749. https://doi.org/10.1101/2021.03. 24.436749 .

[60] Tan, S. et al. Stromal senp1 promotes mouse early folliculogenesis by regulating bmp4 expression. Cell $\mathcal{G}$ Bioscience 7 (1), 36 (2017). https: //doi.org/10.1186/s13578-017-0163-5 .

[61] Lee, J. S. et al. Sumo-specific protease 2 (senp2) suppresses browning of white adipose tissue through c/ebpßmodulation (2020). URL http:// biorxiv.org/lookup/doi/10.1101/2020.12.16.422969. https://doi.org/10. $1101 / 2020.12 .16 .422969$.

[62] López, I. et al. An unanticipated tumor-suppressive role of the sumo pathway in the intestine unveiled by ubc9 haploinsufficiency. Oncogene 39 (43), 6692-6703 (2020). https://doi.org/10.1038/s41388-020-01457-y .

[63] Jang, S. M. et al. Kap1 facilitates reinstatement of heterochromatin after dna replication. Nucleic Acids Research 46 (17), 8788-8802 (2018). https: //doi.org/10.1093/nar/gky580 .

[64] Li, M., Xu, X., Chang, C.-W. \& Liu, Y. Trim28 functions as the sumo e3 ligase for pcna in prevention of transcription induced dna breaks. Proceedings of the National Academy of Sciences 117 (38), 23588-23596 (2020). https://doi.org/10.1073/pnas.2004122117 .

[65] Leclerc, J., Ballotti, R. \& Bertolotto, C. Pathways from senescence to melanoma: focus on mitf sumoylation. Oncogene 36 (48), 6659-6667 (2017). https://doi.org/10.1038/onc.2017.292 . 
bioRxiv preprint doi: httpspringer / fort

10,2022 . The copyright holder for this preprint (which was not certified by peer review) is the author/funder. All rights reserved. No reuse allowed without permission.

[66] Batisse-Lignier, M. et al. P53/rb inhibition induces metastatic adrenocortical carcinomas in a preclinical transgenic model. Oncogene 36 (31), 4445-4456 (2017). https://doi.org/10.1038/onc.2017.54 .

[67] Travers, S. et al. Multiplexed steroid profiling of gluco- and mineralocorticoids pathways using a liquid chromatography tandem mass spectrometry method. The Journal of Steroid Biochemistry and Molecular Biology 165, 202-211 (2017). https://doi.org/10.1016/j.jsbmb.2016.06. 005 .

[68] Bankhead P., F. J. e. a., Loughrey M.B. Qupath: Open source software for digital pathology image analysis. Scientific Reports 7, 16878 (2017). https://doi.org/https://doi.org/10.1038/s41598-017-17204-5 .

[69] Subramanian, A. et al. Gene set enrichment analysis: A knowledge-based approach for interpreting genome-wide expression profiles. Proceedings of the National Academy of Sciences 102 (43), 15545-15550 (2005). https: //doi.org/10.1073/pnas.0506580102 .

[70] Raudvere, U. et al. g:profiler: a web server for functional enrichment analysis and conversions of gene lists (2019 update). Nucleic Acids Research 47 (W1), W191-W198 (2019). https://doi.org/10.1093/nar/ gkz369 .

[71] R Core Team. R: A Language and Environment for Statistical Computing. R Foundation for Statistical Computing, Vienna, Austria (2018). URL https://www.R-project.org/.

Acknowledgements. We thank K. Ouchen, S. Plantade, and P. Mazuel for animal care, C. Damon-Soubeyrand (Anipath-Clermont) and J.P. Saru for their technical assistance, and Y. Renaud for management of the bioinformatic platform.

\section{Authors' contributions.}

Funding. This work was funded through institutional support from CNRS, INSERM, Université Clermont-Auvergne, the French government IDEXISITE initiative 16-IDEX-0001 (CAP 20-25), and grants from Ministère de l'Enseignement Supérieur, de la Recherche et de l'Innovation (to DD), Société Française d'Endocrinologie (to DD and AM), Fondation Association pour la Recherche sur le Cancer (to JW and JO), and Agence Nationale pour la Recherche (ANR-18-CE14-0012-02 Sex-Specs to AL and AM).

\section{Competing interests.}




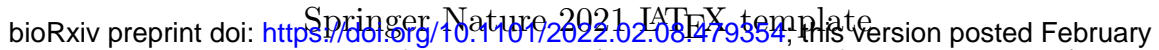
10,2022 . The copyright holder for this preprint (which was not certified by peer review) is the author/funder. All rights reserved. No reuse allowed without permission.

SENP2 controls adrenal cortex homeostasis

\section{Supplementary figures}

A.

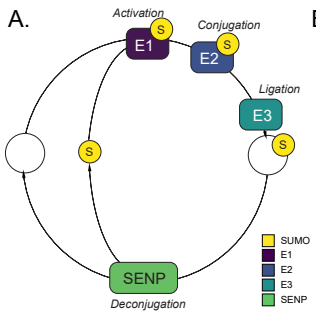

E.

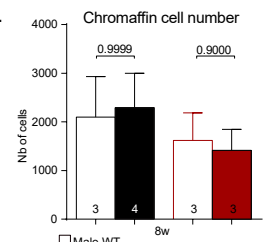

पMale WT $\square$ Female WT

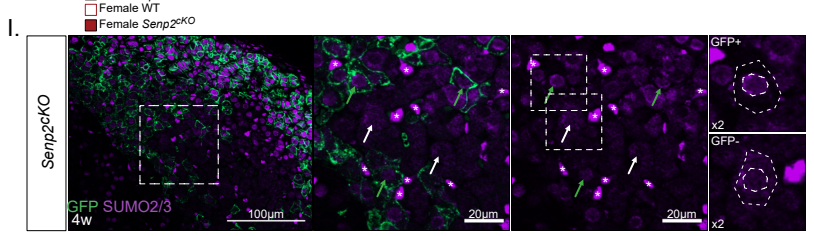

K.

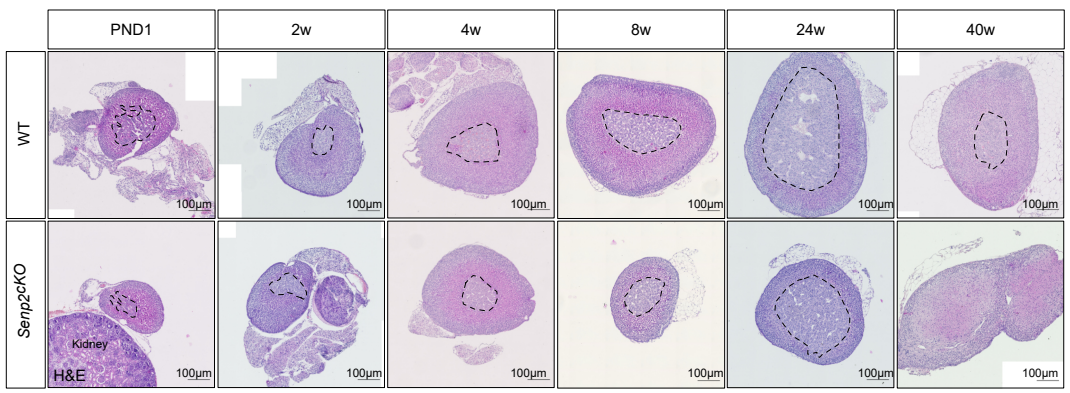

G.

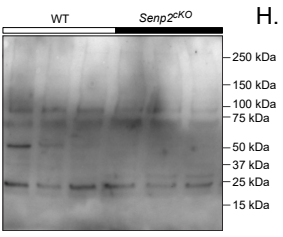

IB: SUMO1

J. Nuclear/cytoplasmic SUMO2/3

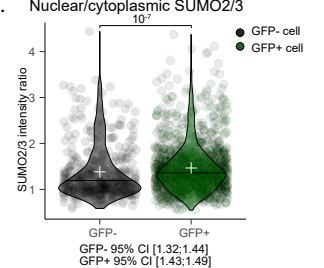

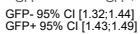

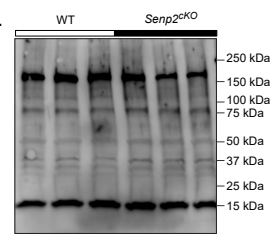

IB : SUMO2/3 - GFP-cell

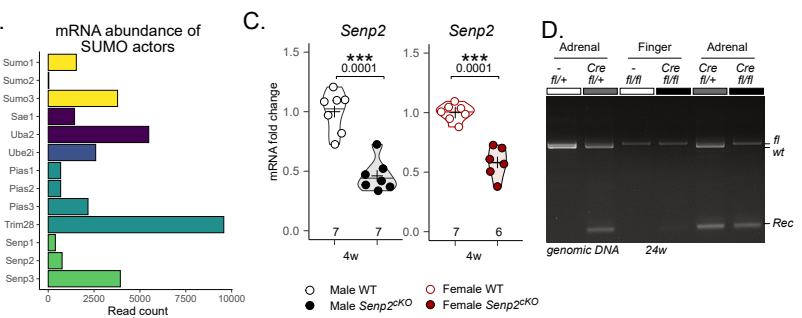

$\mathrm{F}$.
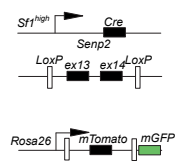

ig.S 1: Related to figure 1

A. Schematic representation of the SUMOylation process

B. Relative abundance of the main actors of SUMOylation in the adrenal gland

C. qPCR analysis of Senp2 mRNA accumulation in 4-week-old adrenals

D. Genomic PCR of Senp2 gene showing specific recombination in $c K O$ adrenals

E. $2 \mathrm{D}$ cell counting number in male and female medulla of WT and Senp $2^{c K O}$ mice

F. Scheme representing genetic model of Senp2 $2^{\text {cKO }}$ and reporter gene Rosa26RmTmG

G. Western blot analysis of SUMO1 in WT and Senp2 $2^{c K O} 4$-week-old adrenals

H. Western blot analysis of SUMO2/3 in WT and Senp2 $2^{c K O} 4$-week-old adrenals

I. Coimmunofluorescent labelling of GFP (green) and SUMO2/3 (purple) in Senp2 $2^{\text {cKO }}$ adrenal cortex at 4 weeks of age. Asterisks represent endothelial cells

J. Quantification of the ratio of nuclear vs cytoplasmic intensity of SUMO2/3 in GFP negative cells vs GFP positive cells in Senp2 $2^{c K O}$ adrenal cortex

K. Ontogenic analysis of adrenal morphology with H\&E staining 
bioRxiv preprint doi: httpspringer 10,2022 . The copyright holder for this preprint (which was not certified by peer review) is the author/funder. All rights reserved. No reuse allowed without permission.

34 SENP2 controls adrenal cortex homeostasis

A.
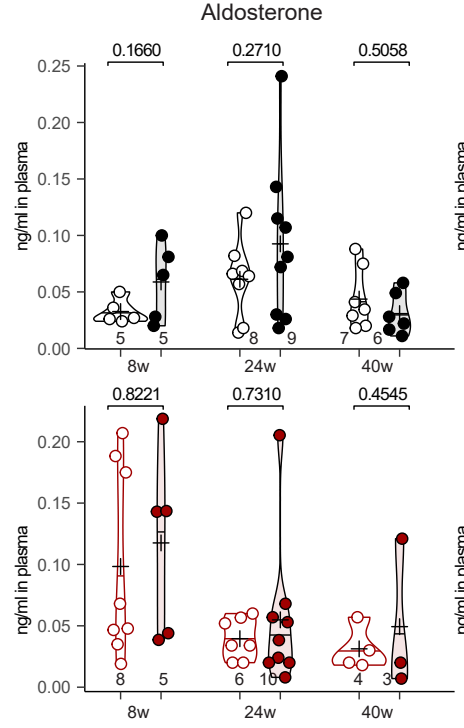

B.

18- $\mathrm{OH}$ corticosterone
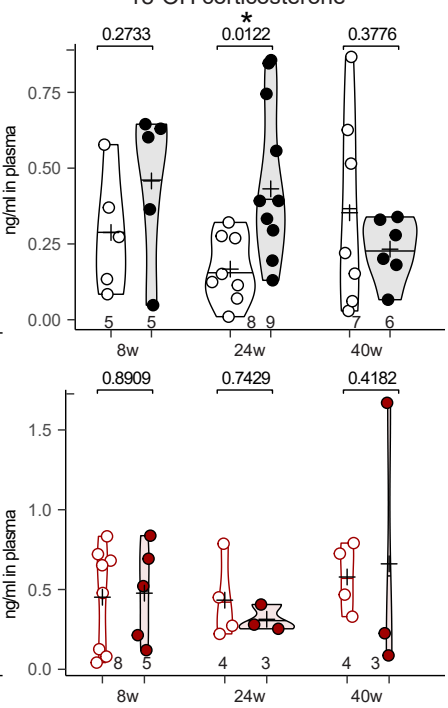

C.
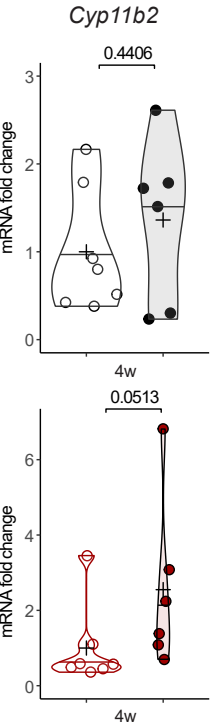

O Male WT

O Female WT

- Male Senp2 $2^{\text {-KO }}$ Female Senp2 $2^{\text {cKO }}$

Fig.S 2: Related to figure 2

A. Plasmatic concentration of aldosterone in WT and $S e n p 2^{c K O}$ at 8,24 and 40 weeks of age (determined by LC-MS/MS).

B. Plasmatic concentration of 18-hydroxy-corticosterone in WT and $S e n p 2^{c K O}$ at 8, 24and 40 weeks of age (determined by LC-MS/MS).

C. qPCR analysis of aldosterone synthase coding gene Cyp11b2 mRNA accumulation in 4-week-old WT and Senp2 $2^{c K O}$ adrenals. 


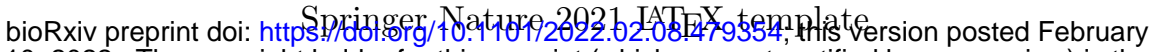
10,2022 . The copyright holder for this preprint (which was not certified by peer review) is the author/funder. All rights reserved. No reuse allowed without permission.
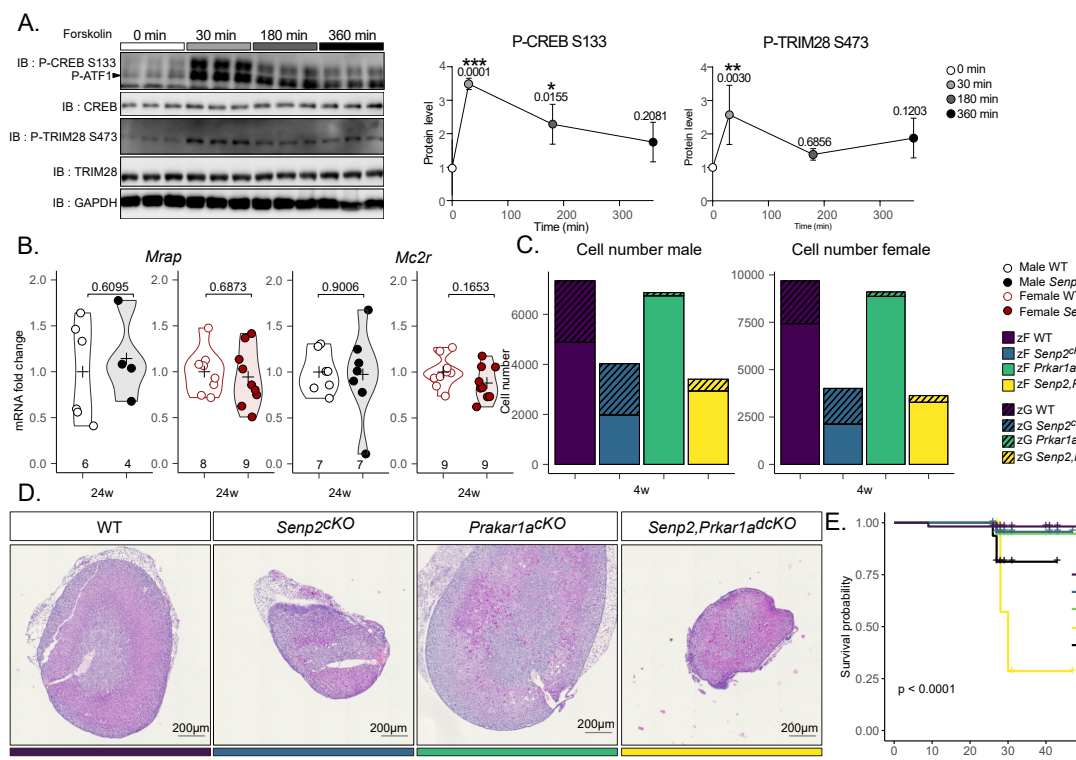

- Male WT - Female Senpzcko $\mathrm{zF}$ WT

ZF Senp2cko zF Senp2,Prkartadcko

zGWT

Z ZG Senp $2^{\text {CKO }}$

ZGG Senp2,Prkar1adcko

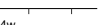

$4 w$

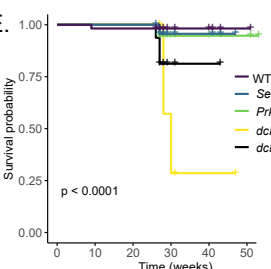

Fig.S 3: Related to figure 3

A. Western blot analysis of the kinetics of CREB and TRIM28 phosphorylation after forskolin treatment in ATC7 cells. $P$-values represent difference between wells treated with vehicle compared to 30,180 and 360 minutes of forskolin.

B. qPCR analysis of ACTH receptor and co-receptor mRNA accumulation in 24-week-old WT and Senp2 $2^{c K O}$ mice.

C. $2 \mathrm{D}$ cell counting number the adrenal cortex of male and female

D. Representative H\&E staining of WT, Senp2 $2^{c K O}$, Prkar $1 a^{c K O}$ or Senp2, Prkar $1 a^{d c K O}$ adrenals

E. Kaplan-Meier curve of double-knockout mice with or without $0.9 \% \mathrm{NaCl}$ treatment 
bioRxiv preprint doi: httpspringer / Fo.

10,2022 . The copyright holder for this preprint (which was not certified by peer review) is the author/funder. All rights reserved. No reuse allowed without permission.

$36 \quad$ SENP2 controls adrenal cortex homeostasis

Table S1 : Mean steroids plasmatic concentrations after 2 hours ACTH treatment

$\mathrm{ACTH}$

\begin{tabular}{lllll} 
& \multicolumn{4}{c}{ Mean concentration + /- SD (p-value compared to vehicle counterpart) } \\
\cline { 2 - 5 } Male & WT & Senp2 cKO & WT & Senp2 cKO \\
\hline Progesterone & $0.15+/-0.09$ & $0.30+/-0.39$ & $9.23+/-4.03(\mathbf{0 . 0 0 0 1})$ & $1.70+/-0.88(\mathbf{0 . 0 4 5 7})$ \\
DOC & $0.31+/-0.29$ & $0.43+/-0.17$ & $24.02+/-18.9(\mathbf{0 . 0 0 0 1})$ & $5.26+/-3.53(\mathbf{0 . 0 4 0 1 )}$ \\
Corticosterone & $26.6+/-13.89$ & $24.39+/-13.36$ & $202.3+/-40.96(\mathbf{0 . 0 0 0 1})$ & $75.53+/-22.10(\mathbf{0 . 0 2 6 7})$ \\
11-DH-cort & $0.13+/-0.11$ & $0.12+/-0.06$ & $0.89+/-0.68(\mathbf{0 . 0 0 0 4})$ & $0.18+/-0.06(0.3815)$
\end{tabular}

\begin{tabular}{lllll} 
& \multicolumn{3}{c}{ Mean concentration + /- SD ( $\mathrm{p}$-value compared to vehicle counterpart) } \\
\cline { 2 - 5 } Female & WT & Senp2 cKO & WT & Senp2 cKO \\
\hline Progesterone & $7.31+/-15.52$ & $5.56+/-11.57$ & $3.55+/-1.62(0.9999)$ & $2.60+/-1.08(0.2182)$ \\
DOC & $4.91+/-4.20$ & $9.65+/-11.53$ & $55.75+/-14.29(\mathbf{0 . 0 0 0 1 )}$ & $28.02+/-13.62(0.0896)$ \\
Corticosterone & $106.70+/-65.69$ & $112.80+/-47.87$ & $334.20+/-67.24(\mathbf{0 . 0 0 0 1})$ & $200.00+/-81.52(\mathbf{0 . 0 1 1 3})$ \\
11-DH-cort & $0.49+/-0.33$ & $0.45+/-0.18$ & $2.30+/-1.01(\mathbf{0 . 0 0 0 1})$ & $0.85+/-0.36(0.1544)$
\end{tabular}

Kruskal-Wallis with planned comparisons using Dunn's test to determine the genotype or treatment effect

Table S 1: Related to figure 3

Mean steroids plasmatic concentrations after 2 hours ACTH treatment 


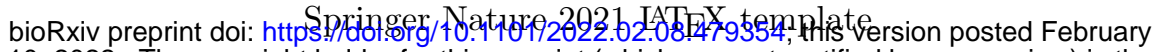
10,2022 . The copyright holder for this preprint (which was not certified by peer review) is the author/funder. All rights reserved. No reuse allowed without permission.

SENP2 controls adrenal cortex homeostasis

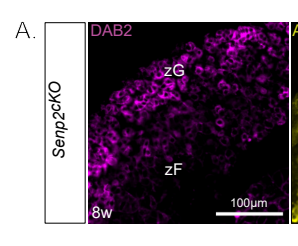

B.

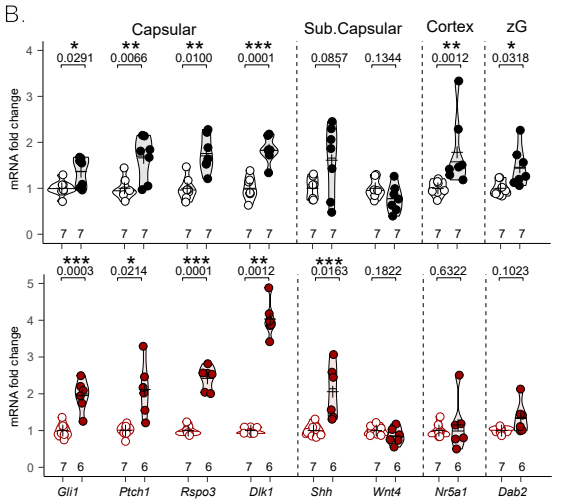

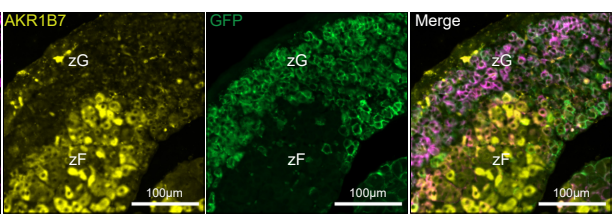

C.

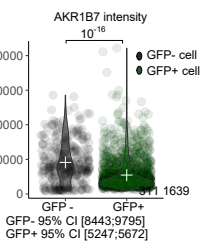

GFP- $95 \% \mathrm{Cl}[8443 ; 9795]$
$\mathrm{GFP}+95 \% \mathrm{Cl}[5247 ; 5672]$
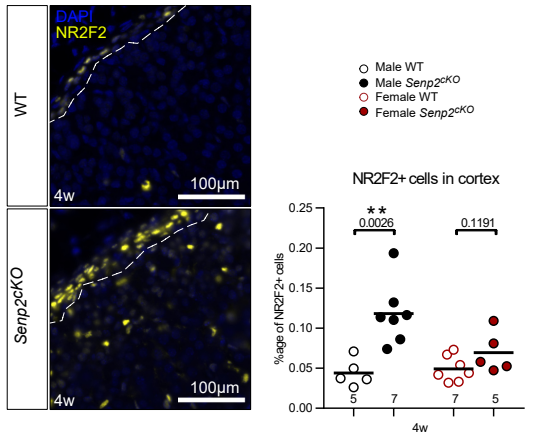

Fig.S 4: Related to figure 4

A. Coimmunofluorescent labelling of AKR1B7 (yellow), GFP (green) and Disabled2 (purple) on 8-week-old Senp $2^{\text {cKO }}$ female adrenal. Quantification of AKR1B7 intensity in GFP+ and GFPSenp2 $2^{\text {cKO }}$ female adrenal cells

B. qPCR analysis of zonal marker mRNA accumulation in 4-week-old WT and Senp $2^{c K O}$ adrenals C. Immunofluorescent labelling of capsular marker NR2F2 (yellow) with nuclei staining with DAPI (blue) and quantification of the proportion of NR2F2+ cells in the adrenal cortex of WT and Senp $2^{\text {cKO }}$ male and female adrenal cortices 


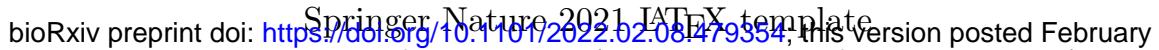
10,2022 . The copyright holder for this preprint (which was not certified by peer review) is the author/funder. All rights reserved. No reuse allowed without permission.

A. Proliferation rate
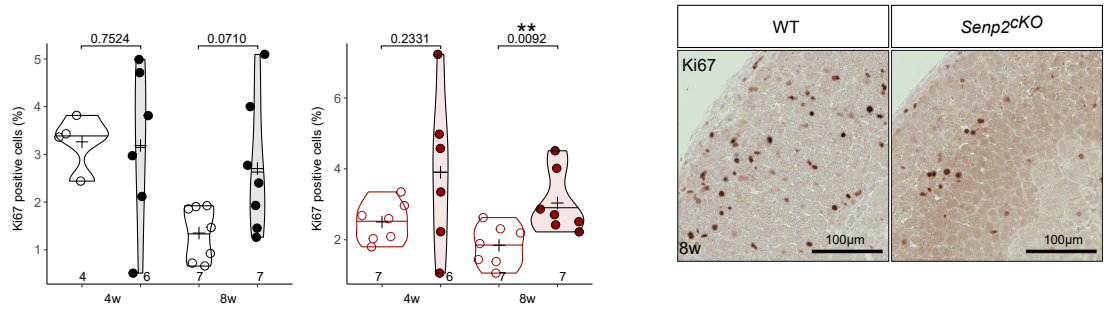

B.
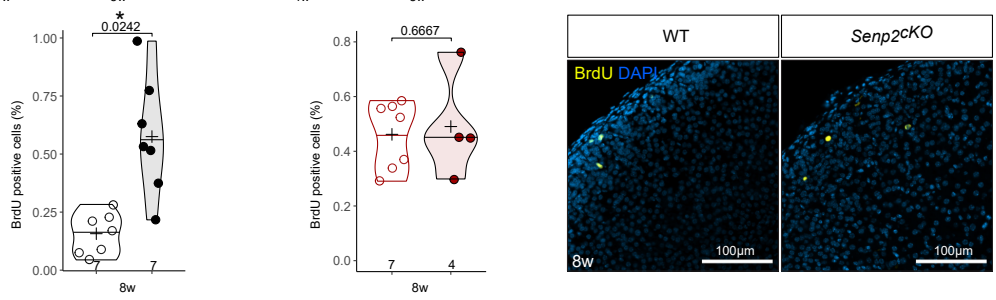

C.
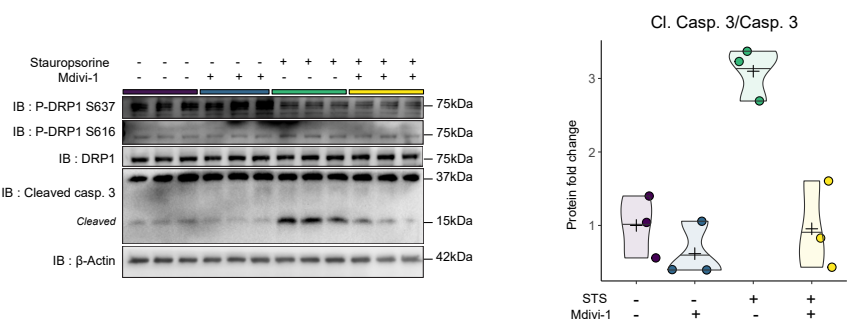

D.

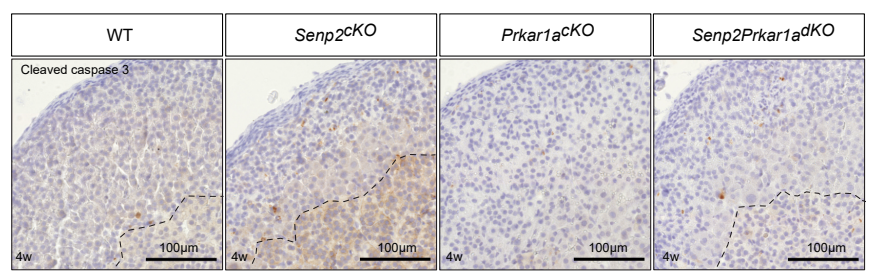

Fig.S 5: Related to figure 5

A. Quantification and representative picture of Ki67 staining on WT and Senp2 $2^{\text {cKO }} 4$ - and 8week-old adrenal cortices

B.Quantification and representative picture of 2 hours BrdU incorporation staining on WT and Senp2 $2^{\text {cKO }}$ 8-week-old adrenal cortices

C. Western blot analysis of phosphorylated and total DRP1 in cells treated with DMSO, DRP1 inhibitor M-divi1 $(10 \mu \mathrm{M})$ and/or Staurosporine $(0.2 \mu \mathrm{M})$.

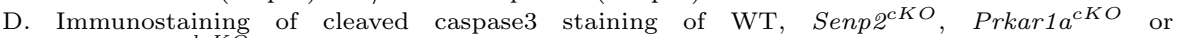
Senp2,Prkar1a $a^{d c K O}$ adrenals 


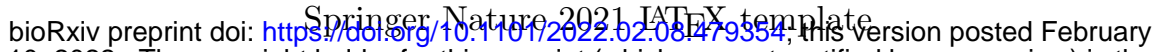
10,2022 . The copyright holder for this preprint (which was not certified by peer review) is the author/funder. All rights reserved. No reuse allowed without permission.

SENP2 controls adrenal cortex homeostasis

A.

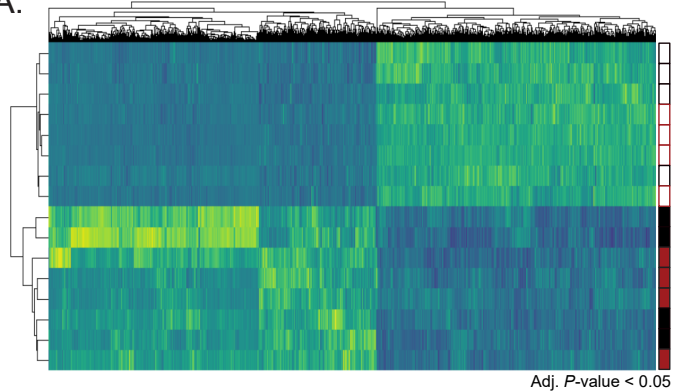

Fig.S 6: Related to figure 6

A. Heatmap representing the median centred expression of dysregulated genes (adjusted $P$-value $<0.05$ between WT and Senp2 $2^{c K O}$ male or female) in 4-week-old male and female, WT and Senp $2^{\text {cKO }}$ adrenals

B. Principal component analysis of gene expression in WT and $\operatorname{Senp} 2^{c K O} 4$-week-old male and female adrenals
B.

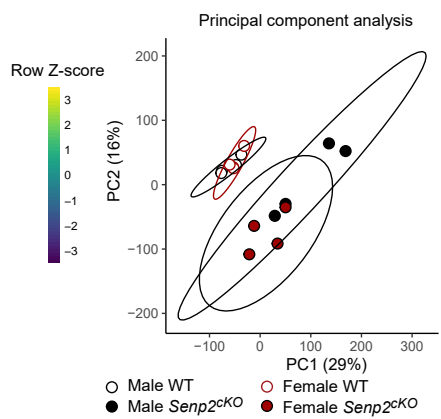

